\title{
Network-driven positive externalities in clean energy technology production: the case of energy efficiency in the EU residential sector
}

\author{
Valeria Costantini ${ }^{1,4} \cdot$ Valerio Leone Sciabolazza $^{2} \cdot$ Elena Paglialunga $^{3,4}$ (D)
}

Accepted: 4 February 2022 / Published online: 28 February 2022

(c) The Author(s) 2022

\begin{abstract}
In this paper, we propose a model of national innovation production that formalizes the role of trade partnerships as a channel of knowledge spillovers across countries. The model is used to investigate the energy efficiency technological domain in the European Union (EU) using a panel database covering 19 EU countries for the time span 1990-2015. The model is estimated by using a novel empirical strategy which allows to assess the knowledge spillover effects benefiting a country depending on its relative position in the trade network, and correct for common endogeneity concerns. We show that being central in the trade network is a significant determinant of a country's innovative performance, and that learning-by-exporting mechanisms are responsible for increased innovation performances. We further reveal that neglecting network effects may significantly reduce our understanding of domestic innovation patterns. Finally, we find that the benefits obtained from knowledge diffusion varies with the domestic absorptive capacity and policy mix composition. Our main implication is that policy design informed by network-based case studies could help maximizing the exploitation of positive knowledge spillovers.
\end{abstract}

Keywords Network analysis · Knowledge spillovers · Technological capability · Energy efficiency $\cdot$ Residential sector

JEL Classification O33 $\cdot \mathrm{O} 38 \cdot \mathrm{Q} 48 \cdot \mathrm{Q} 55$

Elena Paglialunga

elena.paglialunga@uniurb.it

Valeria Costantini

valeria.costantini@uniroma3.it

Valerio Leone Sciabolazza

valerio.leonesciabolazza@uniroma1.it

1 University of Roma Tre, Rome, Italy

2 Sapienza University of Rome, Rome, Italy

3 University of Urbino, Urbino, Italy

4 SEEDS, Ferrara, Italy 


\section{Introduction}

The continuous evolution of green technologies has been fostered by multiple public support instruments and massive investments in eco-innovation. Recently, questions have been raised on the cost effectiveness of these public support measures and scholars are now exploring whether the linkages across industries, technologies and policy instruments can be leveraged to reduce the financial burden of these investments, while remaining on track on a sustainable transition pattern. In this line of research, a large effort is currently dedicated to understand the potential role that co-evolving technological systems and cross-country spillover effects may play. This is done by using sophisticated analytical frameworks building on the well-established acknowledgment of the impact played by (generally-defined) positive externalities in this context. Relevant to this stream of research are those studies including innovation spillovers among the drivers of economic growth and firms productivity at the general level (Evangelista et al., 2018; Lee, 2020; Li and Bosworth, 2020; Mitze and Makkonen, 2020), and acknowledging their beneficial role in specific sectors such as the eco-innovation domain (Costantini et al., 2017a). ${ }^{1}$

The literature focusing on the eco-innovation domain is increasingly interested in the specific set of green technologies related to the energy system (Barbieri et al., 2016; Verdolini and Galeotti, 2011), broadly distinguished between innovation patterns in renewable sources (see Johnstone et al., 2010; Reichardt and Rogge, 2016, among others) and energy efficiency (see for example, Noailly, 2012; Popp, 2002). In this context, the energy system of the European Union (EU) represents an attractive case study. Not only it allows to investigate the role of clean energy technologies in achieving a low carbon society, but it also provides the opportunity to observe how such disruptive technology regime shift generates large structural changes involving the whole economic system. Indeed, this radical change in the technological paradigm of the energy system comprises several transformations that also alter the political and organisation structure (Rosenow et al., 2016; Strunz, 2014).

In general terms, the costs of a successful transition of the energy system toward a more sustainable pattern depends on the structural features of countries, but also on the multiple linkages characterizing technologies, productive sectors and policies. It follows that if we rely on a definition of energy transition as a structural change involving the way energy services are produced, delivered and used, then clearly all these dimensions involved in the change should be jointly addressed, and the regulatory and institutional dynamics required for the transition should be coordinated with the evolution of the technological and economic system (Rosenow et al., 2017). Such a deep transformation of the whole economic system brings unavoidable transaction costs, which can be smoothed if a systemic-evolutionary view is adopted in policy mix design (Nill and Kemp, 2009).

In line with the so-called Porter hypothesis (Porter and Van der Linde, 1995), the regulatory framework may potentially turn adaptation costs into gains if the organisational, institutional and entrepreneurial settings are properly coordinated in exploiting the induced effects on the production and diffusion of the innovative goods and processes required to achieve the environmental targets. In this context, the institutional and socio-economic partnerships between EU members generate a complex web of relations which play a key

\footnotetext{
1 Importantly, also policy spillovers are recently investigated in their capacity to better explain the innovation performance (Dechezleprêtre et al., 2015; Peters et al., 2012), especially in green technologies (Marin and Zanfei, 2019).
} 
role in facilitating the coordination within and between countries for the development and deployment of new technological trajectories (Antonelli et al., 2020).

This coordination require to be analysed from both a top-down and a bottom-up perspective. Top-down actions include, for instance, general policies as the EU Smart Specialisation Strategy (S3) which are designed to overcome the Porter hypothesis, since knowledge co-creation and co-evolving economic systems can be key to transform the challenging goal of a sustainable energy transition into a development opportunity with no geographical boundaries (Santoalha and Boschma, 2020). In so doing, these strategies recognize a crucial role to the potential propelling strength played by spillover effects raising from coinvention activities and technological relatedness, which can help EU countries to speed up in converging toward the top of the learning curve on international markets (Balland et al., 2019; Foray et al., 2011), and motivate the implementation of bottom-up actions. These type of actions, in fact, are strictly related to the improvement of the capacity of agents, firms, regions, and sectors to deploy new green technologies favoured by their pre-existing knowledge base (Montresor and Quatraro, 2020).

Given that a complete empirical analysis involving the whole energy system prevents a deep investigation on the fine-grained top-down and bottom-up mechanisms that can explain the evolution of the sustainable energy transition pathway, we select as a case study the technological domain related to energy efficiency (EE) in the EU residential sector, and we measure the innovation output of countries in terms of patent applications. Three reasons are behind this choice: (i) energy consumption in buildings is a key aspect of the sustainable transition, because one can either face substantial losses due to the increase in energy prices or gain large benefits from innovation and resource efficiency; (ii) the new policy document known as the "Clean energy for all Europeans" package (EC, 2019) puts energy performance in buildings as the first point of the European energy strategy for the next decades, since buildings are responsible for approximately $40 \%$ of energy consumption and $36 \%$ of $\mathrm{CO} 2$ emissions in the EU; (iii) energy efficiency in the residential sector comprises both the production and the consumption side, therefore focusing on this sector allows to conduct a structural change analysis which is well grounded in the analytical framework developed by Cantner and Malerba (2007).

In order to synthesize in a unique empirical approach the two top-down and bottom-up perspectives, we propose an analytical design in which top-down coordination in policy mix design is represented by different indicators computed considering both within and between-country dimensions, while bottom-up coordination is accounted by looking at the positioning of each country within the network of economic and knowledge relations.

With respect to the latter element, we follow existing literature pointing at the role of exporting activities in fostering innovation, and we focus on the investigation of export-led spillover effects. The positive outcome of learning from foreign markets on domestic productivity can derive from both direct and indirect linkages. Buyer-seller relationships may directly increase the knowledge stock of both partners, introducing novelties in the organisational and managerial structure as well as in the technological content of the production process. Indirect effect may arise from the general increase in investments required for the firm to remain competitive on external markets (see among others, Andersson and Lööf, 2009; Bustos, 2011; Lileeva and Trefler, 2010; Liu and Buck, 2007). Moreover, according to Dechezleprêtre and Glachant (2014) the focus on export activities as a driver of knowledge externalities better allows to capture the role of the policy mix design in explaining characteristics of trading partners in terms of dimension and structure of markets.

We look at the economic partnerships between EU members in terms of bilateral export flows of goods and appliances relevant for the EE performance in the residential sector, in 
order to test whether, and to which extent, trade partnerships in a bilateral and multilateral perspective increase the capacity to transform foreign knowledge into domestic innovation opportunities in the EE domain. In so doing, we are able to observe the interaction among foreign agents (customers, competitors, intermediaries) sharing the same market environment (here defined by the specific sector under investigation), and how this may lead to the access to state-of-the-art technologies and cutting-edge knowledge that are not available to those firms only operating in the domestic market (García et al., 2012). In other words, we can investigate how the sector-specific innovation output may benefit from the continuos contamination with external inputs, especially if the firm/sector is well equipped with adequate technological absorptive capacity (Love and Ganotakis 2013; Zhao et al., 2019). Importantly, the adoption of a specific sector as a case study allows, at least partly, solving the criticisms moved by De Loecker (2013) to those empirical exercises based on purely macro-level aggregates.

In this context however, it might be difficult to disentangle whether an increase associated with domestic innovation is mainly driven by the spillover effect associated to the export network itself or by the ability of the country to attract economic partners that are most relevant for knowledge diffusion. In addition, a correct assessment of the benefits accrued from knowledge spillovers may be hindered by the presence of confounding factors, the heterogeneity of industries belonging to different countries, and unobserved factors explaining the interaction between the domestic characteristics and the relative position of the country in the network (Salomon and Jin, 2008).

Recent empirical approaches developed under the umbrella of economic complexity have addressed the issue of heterogeneity of agents and unobservable characteristics with different applications and methodologies. From a general point of view, economic complexity may be defined as the set of differences in available capabilities and their interactions at the country level that might explain differential in income and productivity performances (Hidalgo and Hausmann, 2009; Hidalgo, 2021). In addition, non-linear relationships seem to better define the complexity of products and the fitness of countries which produce them (Tacchella et al., 2012), where the fitness of a country can be defined as the sum of the complexities of its exported products (Pugliese et al., 2017) and higher values are associated with increased probability of high economic growth perspectives with respect to countries with lower fitness (Tacchella et al., 2013).

The modelling exercise of knowledge dynamics seems to particularly benefit from the adoption of a complexity approach developed with a network design which allows precisely detecting the role of heterogeneity of a network in influencing the spillover process (Konno, 2016), with interesting applications to the green economy when differences in the country environmental regulatory setting are addressed (Mealy and Teytelboym, 2020).

In addition, a country/industry becomes competitive in the production of a given good once it has acquired the necessary skills, including knowledge (domestic and/or spilling from abroad). However, the acquisition of adequate capabilities is cumulative and pathdependent, meaning that complex products requiring different and advanced skills will be competitively produced mostly by countries with high fitness. Nonetheless, there are circumstances that facilitate the shift of a country/sector from being a laggard to succeed in catching up with the leaders, depending on the specific features of the laggard as well as its relative position in the network (Sbardella et al., 2018). Accordingly, the structure of the web of linkages might contribute explaining to what extent a country/industry is able to capture innovation and productivity opportunities (Jackson et al., 2017).

Keeping this in mind, we develop an empirical investigation of the innovation dynamics of the energy efficiency in the EU residential sector in a setting where a country's effort 
is triggered by the effort of its economic partners, and the country's outcome is a function of the outcomes of the connected countries and its centrality in the EU network of EE export. Our key research questions are: (i) if trade relations facilitate knowledge diffusion in a typical learning-by-exporting process; (ii) if internal technological capabilities increase the absorptive capacity of external knowledge; (iii) if the heterogeneous patterns of energy transition occurring in different countries, and the relative position of each player within the multilateral network, contribute to shaping domestic innovation performance.

We address the three research questions with a two-step network econometric procedure which allows to jointly account for three main issues raised by the economic complexity literature. First, the role played by unobservable features influencing the absorptive capacity related to the cross-country interactions is sorted out. Second, the network structure is modelled in order to monitor the effect associated to the centrality of single countries (interpreted as market leaders) as well as their proximity to leaders (in the case of laggards). Third, the heterogeneity in absorptive capacity of knowledge spillovers related to internal factors as well as to the relative position within the network is explicitly modelled.

Our results show that maintaining a central position in the network of domain-specific export flows is crucial to magnify the effort exerted by a country in fostering its innovation performance. In other words, the internal absorptive capacity of external knowledge is highly dependent on the relative position of the country within the web of multilateral linkages. Furthermore, the absorptive capacity seems to be magnified for those countries with technological advantages in domain-specific enabling technologies that allow better exploiting knowledge complementarity with trade partners. Finally, the knowledge spillover effect is larger for those countries better equipped with an energy regulatory setting speeding up the sustainable transition process. $^{2}$

The rest of the paper is structured as follows. In Sect. 2 we describe the theoretical framework and econometric modelling approach. Section 3 describes the data used in the empirical analysis. Sections 4, 5, and 6 discuss the empirical models and summarizes the main results. Section 7 concludes and provides the main policy implications.

\section{Theoretical framework and econometric modelling}

\subsection{Modelling the knowledge production function}

At the core of the theory on the generation of new innovation is the hypothesis that new ideas, extant knowledge, and the resources assigned to research and development (R\&D) activities can be represented by a stable relationship (Griliches, 1979; Jaffe, 1986, 1989), commonly formalized through a knowledge production function (KPF) expressed as:

$$
Y_{i t}=F\left(X_{i t}\right)
$$

where new innovation produced by country $i$ at time $t, Y_{i t}$ (in our case the stock of per capita patent applications in residential EE technologies) is generated through a number of

\footnotetext{
${ }^{2}$ It is worth mentioning that the network methodology developed in this paper can be easily adapted to other research questions, by looking for instance at innovation adoption (instead of innovation creation), and with bilateral linkages of the network represented by import (instead of export) flows as the diffusion driver of the embedded technical change.
} 
inputs contained in matrix $X_{i t}$ as for instance investments in R\&D and the knowledge accumulated over time, among the others. ${ }^{3}$

The empirical literature has often operationalized Eq. (1) using a linear function of the kind: ${ }^{4}$

$$
\ln \left(Y_{i t}\right)=\delta+\beta_{1} \ln \left(X_{i t}\right)+\mu_{i}+l_{t}
$$

where the terms $\mu_{i}$ and $l_{t}$ are respectively country and time fixed effects, sorting out from the model specification any unobserved factor which might hinder identification related to time-invariant characteristics of the country and potential trends existing in a specific year for all countries. Finally, $\delta$ is a simple rescaling factor (i.e., the intercept).

A problem inherent in this early formulation of the KPF is that it relies on the strict assumption that countries act in a closed economy, and they do not exchange knowledge. In this paper instead, we follow the approach formulated by more recent studies (Bottazzi and Peri, 2007; Mancusi, 2008) and relax this assumption by considering the case of open economies potentially exchanging knowledge, thus formally introducing positive externalities related to knowledge creation. In practice, we consider an augmented KPF of the form:

$$
Y_{i t}=F\left(X_{i t}, X_{R O W t}\right)
$$

where the term $X_{R O W t}$ represents the accumulated knowledge stemming from the rest of the world $(R O W)$ and benefiting country $i$ 's production of new innovation by adding to the existing domestic knowledge at time $t$. In this model therefore, new innovation produced by country $i$ depends on the inputs devoted to research activities by both $i$ and $R O W$.

In its infant stages, the empirical literature operationalized Eq. (3) through a linear function of the kind:

$$
\ln \left(Y_{i t}\right)=\delta+\beta_{1} \ln \left(X_{i t}\right)+\phi \ln \left(X_{R O W t}\right)+\mu_{i}+l_{t}
$$

where $\phi$ registers the strength of spillover effects that stem from the aggregation of the influences of $R O W$ in expanding $i$ 's existing knowledge.

Clearly, the assumption underlying Eq. (4) is that countries are not independent from each other. The innovation generated by country $i, \ln \left(Y_{i t}\right)$, depends also on the knowledge created by other countries: i.e., the $i^{\text {th }}$ element of variable $\ln \left(X_{R O W t}\right)$ collapses into a single term the knowledge produced by countries other than $i$, and contributing to $i$ 's innovation. This form of cross-correlation existing among countries can be made explicit with the relation:

$$
\ln \left(X_{R O W t}\right)=G_{t} \times \ln \left(Y_{t}\right)
$$

where $G_{t}$ is a $n \times n$ matrix, $n$ being the number of countries included in the sample at time $t$, with the generic element $g_{i j}$ registering the extent to which $i$ benefits from knowledge spillovers stemming from $j$ at time $t$. Formally, Eq. (5) can be considered the representation of the KPF of $R O W$.

Following the seminal work by Anselin et al. (1997), and the subsequent analytical extensions, we explicit this cross-correlation in our equation, by considering the KPF of $R O W$ as

\footnotetext{
3 Observe that it is a standard practice in the literature, confirmed by a large empirical evidence (see for instance Hall et al., 2005), to model the KPF so that inputs devoted to knowledge production by country $i$ at time $t$ affect the generation of ideas by $i$ during that year.

4 From now on, we omit error terms to ease notation.
} 
the main source of knowledge spillovers, and model the KPF in Eq. (4) as a spatial autoregressive process. In matrix form, this is equal to:

$$
\ln \left(Y_{t}\right)=\delta+\beta \ln \left(X_{t}\right)+\phi G_{t} \times \ln \left(Y_{t}\right)+\mu_{i}+t_{t}
$$

In order to make estimation feasible, Eq. (6) is rearranged as follows:

$$
\begin{aligned}
\ln \left(Y_{t}\right) & =\delta+\beta \ln \left(X_{t}\right)+\phi G_{t} \times \ln \left(Y_{t}\right)+\mu_{i}+l_{t} \\
\ln \left(Y_{t}\right)-\phi G_{t} \times \ln \left(Y_{t}\right) & =\delta+\beta \ln \left(X_{t}\right)+\mu_{i}+l_{t} \\
\left(I-\phi G_{t}\right) \times \ln \left(Y_{t}\right) & =\delta+\beta \ln \left(X_{t}\right)+\mu_{i}+l_{t}
\end{aligned}
$$

Then, provided that the parameter $\phi$ is smaller than the spectral radius of matrix $G_{t}$, the term $\left(I-\phi G_{t}\right)$ is invertible and Eq. (6) becomes:

$$
\ln \left(Y_{t}\right)=\left(I-\phi G_{t}\right)^{-1} \times\left(\delta+\beta \ln \left(X_{t}\right)+\mu_{i}+\imath_{t}\right)
$$

\subsection{The role of trade-based network spillovers}

Several contributions approached the study of production knowledge using a spatial autoregressive process similar to that of the KPF presented in Eq. (7) (see for a review Autant-Bernard, 2012). Most relevant to our study is the contribution by Ho et al. (2018), who investigate trade partnerships as the channel mediating knowledge spillovers across countries assuming that the production of knowledge by country $i$ benefits from the spillover effects of the knowledge produced by $i$ 's trading partners. In this formulation, $G$ is interpreted as a matrix representing the international trade network, where the generic element $g_{i j}$ registers the value of bilateral imports between $i$ and $j$. It follows that the term $\phi$ assesses the technological spillover of $i$ 's trading partners contributing to the innovation performance of country $i$. The results presented by Ho et al. (2018) show that the parameter $\phi$ is positive and statistically significant, meaning that the import of goods (and the embodied technology) promotes knowledge flow and technology transfer.

Following this approach, we adopt the international trade network as the term $G$ facilitating the flows of technological externalities across countries. In our case, however, we focus on the export-led channel (see among others, Lileeva and Trefler, 2010; Liu and Buck, 2007), where the term $\phi$ quantifies the learning-by-exporting effect, and when its estimated impact is higher than zero and statistically significant, positive spillover effects are at work.

An interesting feature so far overlooked by the literature in relation to Eq. (7) arises from the interpretation of this equation from a network perspective. Multiplying the term $\left(I-\phi G_{t}\right)^{-1}$ by a vector of ones $(q)$, one obtains a measure of each country's position in the export trade network $G$ mediating technological spillovers across countries. The literature refers to this measure as to Katz-Bonacich centrality (Bonacich, 1972, 1987; Katz, 1953). To understand the intuition behind the Katz-Bonacich centrality, we can re-write $\left(I-\phi G_{t}\right)^{-1} \times q$ using a Taylor expansion as follows:

$$
b\left(G_{t}, \ln \left(Y_{t}\right)\right)=\left(I-\phi G_{t}\right)^{-1} \times q \approx \sum_{k=0}^{\infty} \phi^{k} G_{t}^{k} \times q
$$

Here the $i^{\text {th }}$ row of the matrix $G_{t}^{k}$ keeps tracks of the countries that can be reached by country $i$ in the network $G$ in $k$ steps at time $t$. Thus, if $\phi$ is small enough (i.e. less than the spectral radius of $G)$, it is easy to see that the $i$ th element of vector $b\left(G_{t}, \ln \left(Y_{t}\right)\right)$, that is the 
Katz-Bonacich centrality of country $i$, approximates the number of all countries that can be reached by $i$ through a direct or indirect path in the network, penalizing through the parameter $\phi$ the contributions of distant countries in determining $i$ 's centrality. ${ }^{5}$

Building on this intuition, we replace the vector $q$ in the equation of the Katz-Bonacich centrality, Eq. (8), with a linear formulation of the KPF as Eq. (2).

By virtue of this operation, Eq. (7) becomes:

$$
\begin{aligned}
\ln \left(Y_{t}\right) & =\left(I-\phi G_{t}\right)^{-1} \times q \\
& =\left(I-\phi G_{t}\right)^{-1} \times\left(\delta+\beta X_{t}+\mu_{i}+\iota_{t}\right) \\
& =b\left(G_{t}, \ln \left(Y_{t}\right)\right)
\end{aligned}
$$

This model posits that the outcome of country $i$ depends on the spillover effect generated by the inputs devoted by all countries to innovation activities as registered by Eq. (2), with the contribution of each country weighted by its distance from the position of $i$ in the network, as measured by its Katz-Bonacich centrality, recorded by the term $\left(I-\phi G_{t}\right)^{-1}{ }^{6}$ In this way, it is possible to differentiate the impact of knowledge spillovers on the basis of the relative position of each country within the network, quantifying the role of proximity as suggested by the economic complexity framework. ${ }^{7}$

Equation (9) is the KPF empirically estimated in this work. Formally, it represents the reduced-form of a standard spatial autoregressive model where the innovation performance of countries depends both on domestic inputs and on knowledge spilling from other countries and mediated by their Katz-Bonacich centrality in the network, which determines the extent to which the innovation performance of a country benefits from the innovation outcome from network-connected countries. In this way, we account for a multi-scale measure of proximity that is based on the characteristics of the countries belonging to the network, the strength of the bilateral linkages as well as the absorptive capacity of trade partners. From a theoretical standpoint, this setting is in line with recent contributions highlighting that the benefits provided by external knowledge to domestic innovation is not homogeneous across countries, but it is determined by countries' absorptive capacity and their integration and coordination with $R O W$ (Enkel et al., 2018).

\subsection{Econometric issues}

A threat to the correct identification of spillover effects when estimating our model comes from the potential presence of unobserved characteristics of the exporting country which may bias our estimates if not properly considered. For instance, a source of concern is that innovation and environmental regulations or firms' private investment in R\&D boost the innovation performance of a country. At the same time, these might also induce changes in its economic and industrial structures, resulting in the production of goods embedding the new technologies, and the redirection of export flows towards destination markets with

\footnotetext{
${ }^{5}$ However, in order to observe that the contribution of countries far away is less relevant than that of neighboring countries in determining the centrality of country $i$, one should adopt a more stringent hypothesis on the value of $\phi$ : this should be less than the spectral radius of $G$, and less than 1 .

${ }^{6}$ Of course, the higher is $\phi$, the smaller is the contribution of countries that are far away to the innovation performance of a country.

7 Observe that this approach to modelling spatial autoregressive processes is long consolidated in the economics of networks, and it was first pioneered by the seminal work by Ballester et al. (2006).
} 
a proper absorptive capacity. If this is the case, our estimates would be biased from the presence of an unobserved term $\xi$ (e.g. environmental and/or innovation regulation) which is correlated with both the generation of new knowledge of country $i, \ln \left(Y_{i t}\right)$, and its trading partnerships registered by the network $G_{t}$. While previous literature disregarded this source of concern, we directly tackle this issue by estimating Eq. (9) in two steps using an approach similar to that proposed by Heckman (1979).

In the first step, we estimate a selection model to derive the likelihood for two countries to trade with each other at time $t$ by using an equation similar to that of the gravity models, ${ }^{8}$ that is:

$$
g_{i j t}=\alpha+\gamma\left|z_{i t}-z_{j t}\right|+\mu_{i}+\mu_{j}+t_{t}+\epsilon_{i j t}
$$

where $\alpha$ is a rescaling factor (i.e., the intercept), the term $\left|z_{i t}-z_{j t}\right|$ registers the absolute difference in the characteristics between country $i$ and $j$ driving the likelihood that the two will become trade partners at time $t, \mu_{i}$ and $\mu_{j}$ represent the country fixed effects respectively for country $i$ and $j, l_{t}$ is a time fixed effect, and $\epsilon_{i j t}$ is the unobserved part of the relation between $i$ and $j$ at time $t .^{9}$ The estimation of Eq. (10) is specifically used to derive the term $\epsilon_{i j t}$, that is a direct measure of the selection bias driving the trading partnership between $i$ and $j$ in the network $G$, at time $t$, representing the unobserved characteristics motivating $i$ to export towards $j$.

In the second step of our procedure, we implement a correction for network endogeneity à la Heckman by plugging the measure of the selection bias $\epsilon_{i j t}$ derived from Eq. (10) into Eq. (9) ${ }^{10}$ In practice, this is done by relying on a standard set of assumptions ${ }^{11}$ which allow to derive a single measure for the selection bias stemming from the generic country $i$ and related with all countries $j$, that is $\xi_{i t}=\sum_{j \neq i} \epsilon_{i j t}$, and then augmenting Eq. (9) as follows:

$$
\ln \left(Y_{t}\right)=\delta+\beta X_{t}+\phi G_{t} \times \ln \left(Y_{t}\right)+\psi \xi_{t}+\mu_{i}+u_{t}+u_{t}
$$

Here, the term $\psi \xi_{t}$ captures the selection bias and delivers consistent estimation of Eq. (11), since it controls for the unobserved term that is potentially correlated with both network selection of country $i$ and its innovation capacity, while $\phi$ registers the magnitude of the spillover effect on $i$ 's innovation outcome. Finally, $u_{t}$ indicates the error term. Estimates for this model can be performed using a non-linear least squares estimator (NLLS) and standard errors can be computed using standard bootstrap methods. ${ }^{12}$

\footnotetext{
8 See for a discussion Charbonneau (2017) and Graham (2017).

9 Observe that by including time and country fixed effects, we incorporate in the equation all time-invariant factors driving the formation of trade partnership, such as distance, a shared border, or common language, among others.

10 Observe that this Heckman selection model is identified even without exclusion restrictions. Identification, in this case, exploits non-linearities specific to the network structure of our model. In fact, the dyadspecific regressor term contained in Eq. (10), $\left|z_{i t}-z_{j t}\right|$, is expressed in absolute values of differences, and these differences in characteristics do not appear in the outcome Eq. (9).

11 Specifically, we assume that $U=\left(u_{1}, u_{2}, u_{3}, \ldots, u_{n}\right)^{\prime}$ and $\epsilon_{i}=\left(\epsilon_{i 1}, \epsilon_{i 2}, \ldots, \epsilon_{i n}\right)^{\prime}$ are jointly normal, with $E\left(u_{i}^{2}\right)=\sigma_{u}^{2}, E\left(u_{i} \epsilon_{i j}\right)=\sigma_{u \epsilon}^{2} \forall i \neq j, E\left(\epsilon_{i j} \epsilon_{i k}\right)=\sigma_{\epsilon}^{2} \forall j=k$, and $E\left(\epsilon_{i j} \epsilon_{i k}\right)=0 \forall j \neq k$. Under these assumptions, the expected value of the error term $u$ on the network selection is $E\left(u_{i} \mid \epsilon_{i 1}, \ldots, \epsilon_{i n}\right)=\psi \sum_{j \neq i} \epsilon_{i j}$, where $\psi=\frac{\sigma_{u, \varepsilon}}{\sigma^{2}}$.

12 Battaglini et al. (2022) provide background and further details about this estimation method, together with the relative codes and settings of the $\mathrm{R}$ package to implement it.
} 


\section{Data}

\subsection{The dependent variable}

We construct a panel database considering 19 EU countries covering the time span going from 1990 to $2015 .{ }^{13}$ We begin the discussion by presenting the dependent variable $\ln \left(Y_{i t}\right)$ adopted in this study. This is the innovation produced by country $i$ at time $t$, and it is measured by computing the country's patent stock in residential EE technologies for a given year, scaled by the population and taken in logarithm. ${ }^{14}$

We rely on the count of patent applications to the European Patent Office (EPO). The choice of the EPO database relies on two main reasons: (i) all countries in the panel belong to Europe so that the protection of the invention on the European market represents the best pay-off solution in terms of costs and benefits from the firm's perspective; (ii) inventions covered by EPO patents are considered as representative of those innovations that are more profitable as filling to EPO is more expensive than to a national patent office. Indeed, as international applications can be very expensive, a deliberate choice about where to file a patent application is part of a firm's innovation strategy (Clarke, 2018; Kim and Lee, 2015). Data, available from OECD data portal, are constructed by using information from the Worldwide Patent Statistical Database (PATSTAT) and eco-innovations are identified through search algorithms for environment-related technologies developed by OECD. Patent statistics provides information about published applications for patents by country's inventor, and fractional counting is applied in those cases where inventors belong to different countries. ${ }^{15}$

The patents considered to construct our dependent variable are those classified in five technological domains relevant for the EE performance in the residential building sector, namely those categorized by the Y02 Cooperative Patent Classification (CPC) as: lighting, heating and cooling, ventilation or air conditioning, home appliances, ICT, and end-user technologies (see Table 6 in the "Appendix" for additional details). ${ }^{16}$ Patents in this specific technological domain are recognized as particularly relevant within the EU Energy and Climate strategy in light of the increasing committent to ensure a clean, but also fair energy transition for all citizens, and have been promoted from both the Energy Union R\&I and Competitiveness priority on "Smart EU energy system with consumers at the centre"

\footnotetext{
13 We select all EU member states for which we have full data availability for the time period considered. Accordingly, the countries contained in our dataset are: Austria, Belgium, Czech Republic, Denmark, Estonia, Finland, France, Germany, Greece, Hungary, Ireland, Italy, Netherlands, Poland, Portugal, Slovak Republic, Spain, Sweden, United Kingdom.

14 This is a standard approach to measuring innovation output, widely used by the economic literature. We acknowledge that this measure may entail drawbacks (Griliches, 1990; Jaffe and Trajtenberg, 2002). Although patent statistics provide very detailed information on the technological characteristics of the invention (with quite an extensive coverage both in space and time), not all inventions are patented and some forms of innovation can be over-represented with respect to others (e.g. product innovations). For further details about the use of patents as an innovation indicator in the environmental-friendly domains see Kemp and Pearson (2007).

15 We acknowledge that the use of EPO patents is an underestimation of the overall innovative capacity at the country level since many inventions are registered only in national patent offices. At the same time, this is a standard procedure in cross-country analyses in order to have comparable values that are not biased by country-specific characteristics of the national patent systems.

${ }^{16}$ We consider the priority date (i.e., first filing date worldwide) since it is the closest to the actual date of invention.
} 
and in the Strategic Energy Technology Plan actions "Smart solutions for consumers". This is the reason behind the focus on the well-detailed classification of patent families developed under the European Commission supervision (Fiorini et al., 2017). The residential EE technologies registered at the EPO account for about $3 \%$ of total patents on average, showing an increasing trend along the entire time period here analysed (1990-2015), but also a wide heterogeneity among the $19 \mathrm{EU}$ countries. The growth rates of total and EE patents from 1995 to 2015 are, respectively, $87 \%$ and $300 \%$, which determine the larger share of EE patents in more recent years. ${ }^{17}$ In terms of patent mix, among the five EE patent subclasses, the share of the ICT domain increased considerably during the period under analysis, ranging from $5.6 \%$ in 1990 to $35.5 \%$ in 2015 . Looking at the cross-sectional dimension, EU countries are characterised by different levels of specialization and diversification over the five technological domains. Eastern European countries, for example, are among the most specialized in residential EE technologies (with a share of around 6\% of total patents compared to $1.75 \%$ for EU15 countries on average, and with peaks over $20 \%$ in selected countries and years).

In line with Hall et al. (2005), we calculate the patent stock measure by applying a Perpetual Inventory Method (PIM) with a continuous discount approach to the number of patent applications filed by a country at time $t$. Put in formula, our dependent variable is: ${ }^{18}$

$$
\text { Patent stock } p c_{i t}=\ln \left(\frac{\sum_{s=0}^{t}\left(\text { Patent }_{i s} \times e^{[-d(t-s)]}\right)}{\text { Population }_{i t}}\right)
$$

where the decay rate $d$ is equal to $15 \%$, as suggested by OECD (2009). The value of Patent stock is scaled by the population count for each country $i$ at time $t$ (as registered in the database EUROSTAT), in order to adjust for the size of the country. ${ }^{19}$

\subsection{The domestic innovation drivers}

Turning to the domestic drivers of innovation included in the KPF, we distinguish them in two broad categories, related to the policy mix design and to the absorptive capacity of the specific technologies under scrutiny.

The first group is created following the recent contributions on the role of the policy mix in inducing eco-innovation (see for example, Costantini et al., 2017b; Rogge and Reichardt, 2016), and it includes the technology-push and demand-pull effects resulting from the implementation policy instruments.

The technology-push factor registers the effort to support invention activities and promote the deployment of new technologies financed by public budget. This is commonly measured using the log transformation of a country's R\&D stock, which we obtained by applying the PIM with a decay rate $d=15 \%$ to the country's public R\&D investments in EE expressed in constant 2010 USD scaled by the country population. Original data on annual public expenditures in $R \& D$ related to the energy sector are taken from the IEA

\footnotetext{
17 By comparing 1990 and 2015, the growth rate in EE patents is almost five times larger that the growth rate registered for total patents.

18 This implies assuming cumulativeness and obsolescence of technological knowledge over time (Griliches, 1979).

19 Alternative decay rates equal to $10 \%$ and $20 \%$ have been tested for robustness. Results remain stable in signs and statistical significance, and they are available upon request from the authors.
} 
energy technology $R D \& D$ budget databases. Energy R\&D flows cover basic and applied research activities and experimental development related to technologies to generate, distribute, monitor and use energy, but exclude demonstration and deployment activities. We refer to this variable as the technology-push policy indicator.

The demand-pull factor is instead a measure of how the policy stringency (commonly measured by energy taxation) influences energy prices and consequently changes demand patterns in residential energy consumption. In building this indicator, we rely on the EUROSTAT electricity and natural gas prices and taxes and the energy balances databases, which provide annual data on prices and taxes distinguishing by end-users type (households and industrial) and by different levels of taxation (e.g., excluding taxes and levies; excluding VAT and other recoverable taxes; including all taxes, levies and VAT), and data on annual consumption of distinguished energy commodities. Accordingly, we select indicators specific for domestic consumers, corresponding to small households (e.g. electricity consumption for dwellings of about $70 \mathrm{~m}^{2}$, and natural gas used for cooking, water and central heating). The final demand-pull variable is obtained by calculating the average energy tax rate in the residential sector as an ad valorem equivalent on energy market price (USD at constant 2010 prices per toe of energy consumed) scaled by the final consumption expenditure of households as follows:

$$
\text { Demand }- \text { pull }_{i t}=\frac{\sum_{n=1}^{2}\left(\text { Energy tax }_{i t}^{n} \times \text { Energy consumption }_{i t}^{n}\right)}{\sum_{n=1}^{2}\left(\text { Energy price }_{i t}^{n} \times \text { Energy consumption }_{i t}^{n}\right)}
$$

where $n$ indexes energy commodities mainly consumed in the residential sector (namely, electricity and natural gas). We refer to this variable as the demand-pull policy indicator.

The second group of covariates aims at registering the key role played by the absorptive capacity of a country in explaining the opportunity to catch advantage from knowledge spillovers. Specifically, we consider three alternative aspects of the technological capability of a country in this specific domain. First, we consider a measure of specialization in Key Enabling Technologies (KETs) since they are multi-purpose in their final use, with horizontal and rare properties that are suitable to be combined with other types of inventions and are largely promoted by the program of the European sustainable energy transition strategy (Foray et al., 2009). According to Montresor and Quatraro (2020), the capacity to develop and exploit new green technologies is favoured by the existence of a horizontally available knowledge base well represented by KETs. This effect is further reinforced by the relatedness of KETs to the technological domain under scrutiny. Accordingly, the patents here categorized as KETs are those included in two specific classes of the EE domain: Information and Communication Technologies (ICT) and End-use technologies, collected under the Y02D $(10,30,50,70)$ and Y02B 70 CPC codes, respectively. These two codes include, for example, devices for reducing energy-consumption in wireline and wireless communication networks, smart grids, electric power management and systems integrating power-related technologies. Patents falling under this category refer to technologies that can be embedded in several different devices and appliances, with the major scope of reducing energy consumption or maximizing EE (EC, 2014). The technological specialization of a country is calculated as the share of KETs stock over the total stock of patents in EE for each country $i$ and year $t$, and we refer to it as KET-share.

A second alternative variable within this second group is a measure of technological advantages in KETs as developed by Soete (1987) and Cantwell (1989), extensively applied in the analysis of countries' innovation and specialization performance (see Evangelista 
et al., 2018; Montresor and Quatraro, 2017, among others). Similar to the trade specialization indicator developed by Balassa (1965), the revealed technology advantage (RTA) here adopted measures the relative strength of each EU country in the KETs classes, compared to all EU countries included in the sample. We refer to this variable as KET-RTA and we compute it as follows:

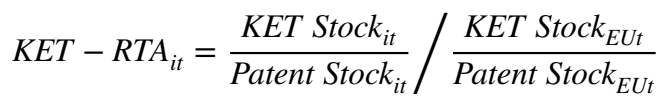

where a value larger than 1 for country $i$ in year $t$ indicates that it has a specialization in KETs higher than the EU average.

The third alternative measure is based on the notion of knowledge diversification, a factor deemed strategic for the diffusion of innovation by the literature (see for instance Huang and Chen, 2010). This is proxied by a variable registering the composition of a country's knowledge stock in terms of variety of patents developed within individual EE technology domains. Similar to Kim et al. (2016) and Leten et al. (2007), we investigate whether technological diversification might spur innovation performance, e.g. through larger economies of scope from R\&D activities. In particular, we follow the common approach of measuring the country's technological diversification using the modified Herfindahl-Hirschman Index (HHI) (as for example in, Chiu et al., 2008; Garcia-Vega, 2006; Lin and Chang, 2015; Quintana-García and Benavides-Velasco, 2008). Accordingly, our indicator of Patent variety is given by the modified HHI and calculated as:

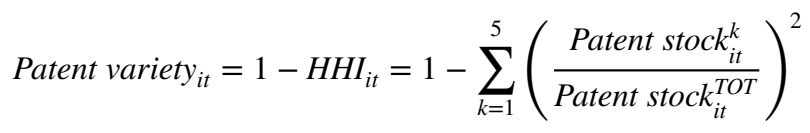

where the ratio in parenthesis represents the share of patent stock over the total stock of EE patent for each $k^{\text {th }}$ of the five CPC-Y02 sub-classes here considered (see Table 6) in country $i$ and year $t^{20}$

\subsection{The knowledge spillover effects}

Turning to the potential mechanism causing spillover effects, that is the cross-country correlation among the domestic patterns of innovations, this is operationalized with matrix $G_{t}$ in Eq. (11). Specifically, we measure the generic connection $g_{i j t}$ using the value of export, from $i$ to $j$ at time $t$, of those EE household-type appliances and equipment (laundry, refrigerators, dishwashing machines, electromechanical and electro-thermic appliances, boilers and lighting fittings) closely related to the EE technological domain in terms of patent activities. Data is retrieved from the United Nations COMTRADE database and expressed in constant 2010 USD (additional details are presented in Table 7 of the Appendix). The implication of using trade data is that the matrix $G_{t}$ is a directed weighted network, where the bilateral relation between $i$ and $j$ postulates that the influence exerted by country $j$ over $i$ might be different from that exerted by $i$ over $j$, depending on the value of their respective

\footnotetext{
${ }^{20}$ Robustness checks have been conducted by using an alternative measure of patent variety adjusted by the total number of patents as suggested by Hall (2005) to correct for potential bias in Herfindahl-type measures applied to count data. Results remain stable in sign and statistical significance and they are available upon request from the authors.
} 
export. In order to account for the relative importance of each partner for the spillover benefiting each country, $G_{t}$ is column-normalized. ${ }^{21}$ An instance of the network structure for the years 1995, 2005, and 2015 is provided in Fig. 4 of the "Appendix".

Two main mechanisms are explained by these data. On the one hand, if the export flow is directed toward a market better equipped in terms of technological capabilities, there is larger scope for learning and upgrading. On the other hand, exporting to larger destination markets (with higher demand growth potential) enhances the incentive to invest in innovative activities as the expected sales and profits grow (Fassio, 2018). It follows that the benefits exerted from spillover effects will also depend on the trading partners characteristics, and should be assessed by looking at the position of a country in the trade network.

Finally, we select a number of variables in order to assess the propensity of countries to trade with each other in network $G$, and model the selection process in our estimation strategy represented by Eq. (10) of the two-step procedure proposed in Sect. 2.3. First, we consider the proximity of countries motivating the creation of export relationships by accounting for all the variables included in the KPF considered in this study: i.e., technology-push, demand-pull, KET-share, KET-RTA and patent variety. Proximity relative to each of these variables is measured by taking the absolute difference between the values of the variable for each $i j$ country pair. Second, we consider proximity in terms of general knowledge production capacity, another crucial driver of trading relationships. This is proxied by the absolute difference in per capita GDP between two countries, at constant 2010 USD logtransformed values (retrieved from the OECD Statistics National Accounts database). ${ }^{22}$ All these variables are used to proxy the term $\left|z_{i t}-z_{j t}\right|$ in Eq. (10).

\section{The export-led network relevance for knowledge spillovers}

The results obtained from the investigation of our first research question are presented in Table 1 where we report the second-step estimation of Eq. (11). As a benchmark, column (1) reports the OLS fixed effects estimates of a traditional KPF as in Eq. (1), in which the innovation performance of EU countries is explained only using the domestic knowledge and resources assigned to $\mathrm{R} \& \mathrm{D}$, and assuming that countries act in a closed economy and knowledge is not exchanged across countries (i.e. $\phi=0$ ). The results are consistent with well-established findings: an increase in the stock of public R\&D in EE by country $i$, as proxied by the variable technology-push, increases its innovation performance in the EE technological domain as measured by Patent stock.

Column (2) presents the NLLS estimates of a KPF positing the existence of knowledge spillover effects as modelled in Eq. (9). ${ }^{23}$ Here, we use the network $G$ of bilateral exports in EE household-type appliances and equipment without controlling for network endogeneity.

\footnotetext{
${ }^{21}$ In a robustness check, we also use a different normalization by dividing each trade flow by the sum of the population of trade partners, and then we column normalize the matrix. Results are available upon request from the authors.

22 As a robustness check, this term is replaced with a variable specifically related to the national innovation system, namely the percentage of people employed in science and technology with respect to the active population (from EUROSTAT database on human resources in science and technology, HRST).

23 Some caution should be used when interpreting the results from this model. The reason is that our data allows to consider the centrality of a country only within the European export network. Moreover, some risks arise from the fact that our data may not be perfect in registering connections among countries (e.g. import and export data not always report consistent information).
} 


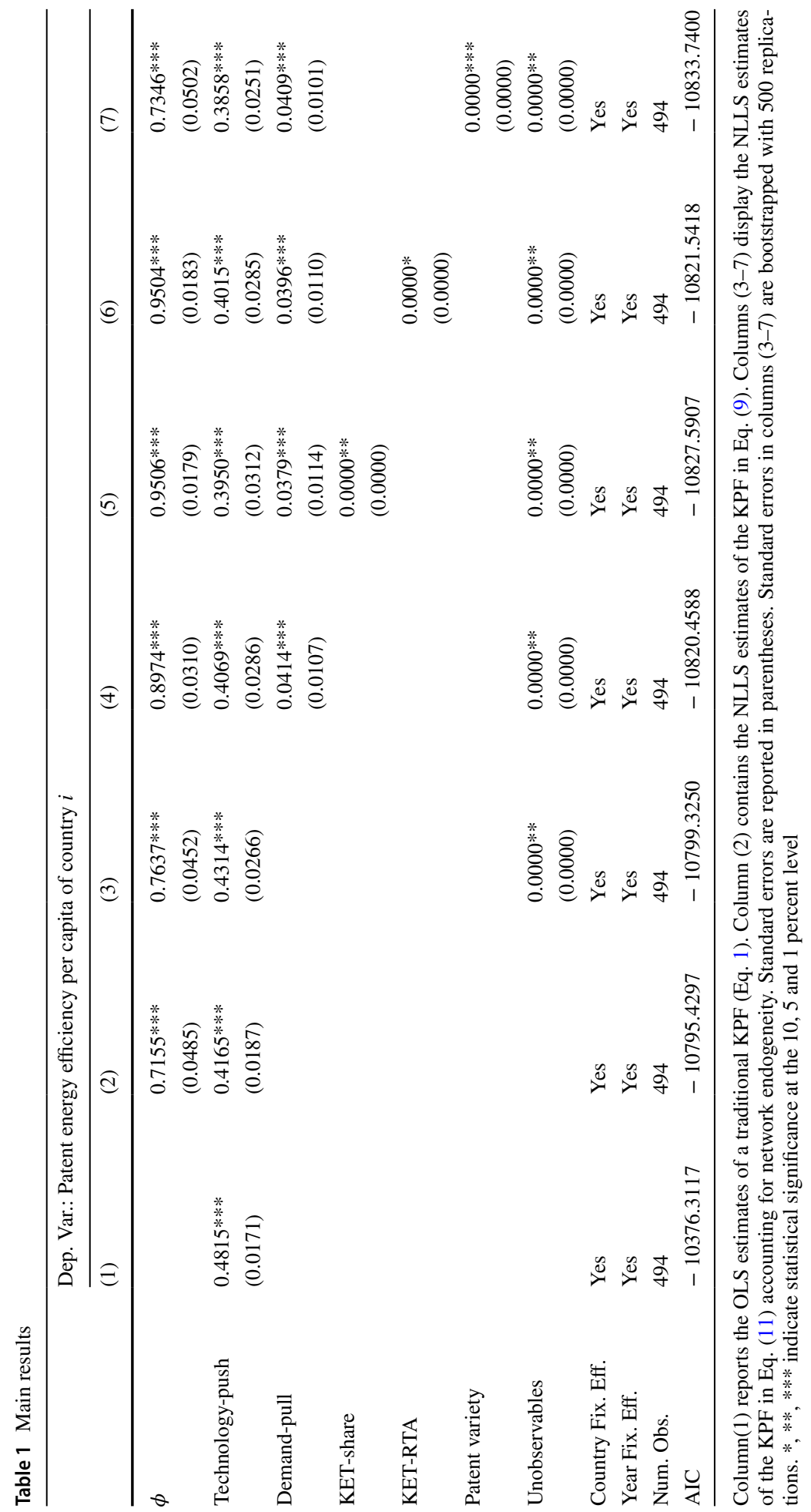


In line with Ho et al. (2018), we find a positive and statistically significant effect of spillovers on domestic innovation performances as $\phi>0$. Moreover, since the goodness of fit of this model, as measured by the Akaike Information Criterion (AIC), improves with respect to that in Column (1), we conclude that accounting for knowledge spillovers across countries increases our understanding of country's innovative performance.

Column (3) displays the results of Eq. (11) where, in addition to the knowledge spillover effect $(\phi)$, we further control for network endogeneity. ${ }^{24}$ The coefficient of the selection correction term (reported in Table 1 as Unobservables) is small but statistically significant and this is consistent with the presence of some unobservable characteristics correlated with both the innovation performance of country $i$ and $i$ 's ability to establish trade partnerships. Second, the AIC value shows a further improvement with respect to previous specifications as the model implemented in Column (3) outperforms the goodness of fit of models in Columns (1) and (2). Third, and most importantly, estimates in Column (3) confirm the positive and statistically significant effect of $\phi$ while increasing its coefficient value with respect to Column (2), meaning that this is a key aspect to be introduced in an economic complexity approach since neglecting the issue of endogeneity produces an underestimation of spillover effects. ${ }^{25}$

It is worth stressing that the coefficient of the variable technology-push retains the same sign and statistical significance across models from Column (1) to (3). However, the interpretation and magnitude of its effects differ. When including knowledge spillover effects into the model, the marginal effect of technology-push is not given by $\beta$ any more, but:

$$
(I-\phi G)^{-1} \beta
$$

This is a $n \times n$ matrix. Here, the $i^{\text {th }}$ element on the diagonal registers the direct effect of a change in i's investment in R\&D (technology-push), on its production of innovation (patent stock). Complementing with this, the generic off-diagonal element $i j^{\text {th }}$ records the spillover effect produced by a change of technology-push in country $j$ and increasing the value of patent stock featured by country $i$. The magnitude of such spillover effect is weighted by the distance of $i$ from $j$. It follows that the marginal effects of technology-push are heterogeneous across countries, and they are determined by the position of the country in the network of EE export $G$. By comparing different effects, those directly related to technology-push in Column (1) obtained with an OLS estimator corresponds to the coefficient $\beta=0.4815$, while the marginal effect in Column (3) is 0.5022 plus an average indirect effect quantified as 0.0742 , suggesting that standard estimates neglecting network spillovers tend to understate the effect of the R\&D investments. ${ }^{26}$

In Column (4), we include the demand-pull indicator as the second main instrument forming the policy mix, and control for the stringency of the price-based measures implemented by a country in stimulating a dynamic growth of demand and market size for new

\footnotetext{
${ }^{24}$ Estimates of the selection model, as Eq. (10), are presented in Table (4). When testing the robustness of our results to the choice of the selection model, by replacing the term GDP with the number of persons employed in science and technology as percentage of active population, we find that our results are qualitatively unchanged, since estimates from both the first and the second stage are substantially unaffected. Results are available upon request from the authors.

25 As a robustness check, we have estimated Eq. (11), Columns (3-7) as in Table 1, by using the network $G$ of bilateral imports, as in Ho et al. (2018), in the same digits as for exports and results remain stable in signs and statistically significant. Results are available upon request from the authors.

${ }^{26}$ Results are available in the "Appendix", Table 5.
} 
technologies (Del Río, 2010). Our results confirm that, in addition to the positive role of technology-push policies, also the demand-pull factor has a positive and statistically significant coefficient. This result confirms existing evidence about the role of demand side (price-based) measures (i.e., energy taxation) in stimulating the innovation performance. When computing marginal direct and indirect effects for the two measures here adopted to proxy the policy mix design, both direct and indirect effects related to the technologypush dimension are substantially higher than those arising from the demand-pull stimulus. While the difference in direct effects between the two instruments is consistent with findings in Costantini et al. (2017b), the higher strength of the spillover effects associated to efforts in R\&D support (the indirect margins are equal to 0.188 and 0.019 for technologypush and demand-pull, respectively) contrasts with previous findings on the predominant role played by demand-driven spillovers. This divergence can be explained by the greater efficiency of our model in capturing the multiple network-related channels responsible for externalities, thus opening new opportunities in research design when complex systems are under investigation.

With respect to the second research question, we test the role of the absorptive capacity of countries into our model specification, in order to sort out from our KPF an unobserved factor which might be potentially relevant to explain the national creation of knowledge. Accordingly, from Column (5) to (7) we include into our model specification the three alternative indicators used to characterize the domain-specific technological capability of countries, namely, the share of patents in KETs (KET-share), the variable indicating whether country $i$ exhibits a RTA in KETs (KET-RTA), and the diversification in knowledge production (patent variety). In all the three cases, the coefficients are small but statistically significant and the measure of goodness of fit shows further improvements. Most importantly, all our predictions are confirmed since both the spillover effect $(\phi)$ and the selection correction term (Unobservables) maintain their sign and statistical significance. This suggests that the absorptive capacity of countries may represent an important input of their KPF. At the same time, this input does not significantly interfere with our understanding of the role played by knowledge spillover effects. ${ }^{27}$

\section{The Katz-Bonacich centrality as a complex measure of proximity}

In order to test the third research question we use Eq. (8) to compute the Katz-Bonacich centrality of countries in network $G$ in different years. The value of $\phi$ in the equation is retrieved from estimates in Table 1. Specifically, the value of $\phi$ is obtained from the model specification in Table 1 , Column (4) with $\phi=0.8974 .{ }^{28}$ The Katz-Bonacich centrality obtained in this way is used to describe the spatial and temporal processes underlying the innovation patterns by introducing the role played by the relative position and the strength of linkages emerging across the network.

\footnotetext{
27 We further test the robustness of our results to the inclusion of other potentially relevant inputs such as the general propensity to generate domestic knowledge (proxied by the patent stock in non-EE technology per capita), the lagged patent stock (5-year lag), and by including the 1-year lag of all explanatory variables. Results remain unchanged in signs and statistical significance, and they are available upon request from the authors.

${ }^{28}$ Observe however that results are qualitatively unchanged when using the value of $\phi$ presented in columns (3), (5), (6), and (7) of Table 1. Results are available upon request from the authors.
} 
Figure 1 shows the top 10 EU countries in terms of Katz-Bonacich centralities in 2015, and their evolution over time from 1990 (i.e. the first year considered in this study). In all years, Germany's centrality clearly outruns all other countries, although its relative importance decreases in recent years. Second and third most-connected countries are respectively France and the UK. The two countries are found with a similar value of Katz-Bonacich centrality in 2015 meaning that they benefit from similar spillover effects. However, while France maintains a relatively stable position in the network and constantly features a high Katz-Bonacich centrality, the UK presents a more unstable evolution. As for the remaining countries, we observe a process of convergence to a similar centrality value in some cases. This is for instance the catch-up process followed by Poland, which describes a typical leading-laggard proximity effect. In other cases instead, we register a process of divergence: i.e. countries (e.g. Netherlands) decreasing their network centrality over time.

This is a significant evidence of a change in the benefits from spillover effects obtained by countries at the individual level. In fact, countries such as Poland have experienced an increase in their network centrality, and moved closer to high performing countries in terms of innovation development, e.g. Germany, thus benefiting from higher spillover effects likely because of their spatial proximity to leading (central) countries. On the contrary, countries like the Netherlands moved from the core to a more peripheral position within the network, benefiting from milder spillover effects in recent years. ${ }^{29}$

We now examine the spatial distribution of Katz-Bonacich centrality in the European geographic space. This is summarized in Fig. 2, where we represent the map of EU countries in 1995 and 2015. In each map, countries are assigned to a specific colour, with darker hues indicating countries with a higher Katz-Bonacich centrality in the network at a given year. The map clearly shows the predominant but partly decreasing centrality of Germany over time. Germany has always the darkest colour, but this tends to fade from 1995 to 2015. At the same time, we find evidence of a change in position of many countries in the network. Colours get darker for some countries, signalling that they are moving to the centre of the network and improving the extent to which they benefit from spillover effects (Poland and Sweden), while they get lighter for other countries (Belgium and the Netherlands), showing that these are shifting towards the fringe of the network, where spillovers are smaller.

We then study the role of the geographical space in determining the benefits derived from spillover effects, by looking at the extent to which the Katz-Bonacich centrality of one country is spatially-autocorrelated with neighbouring countries. To this purpose, we compute the Global Moran Index (GMI) of the Katz-Bonacich centrality of countries in each considered year. The GMI is a metric comprised between -1 and 1 . When it approaches 1, it indicates the presence of clusters, with countries characterised by high (low) centrality value located close to one another in the geographical space. When it is close to -1 , it signals the presence of hot spots: there are different countries with a high (low) network centrality each of them surrounded by a selected group of countries with

\footnotetext{
${ }^{29}$ Katz-Bonacich centrality is the least sensitive centrality measure in terms of a random or systematic variation of the network structure (Bolland, 1988), and one should be really concerned with the sensitivity of this measure only when dealing with random networks (Ghoshal and Barabási, 2011), which is not our case. Still, structural variations in the network across time may represent a confounding factor in our exercise. For this reason, we also replicate Fig. 1 considering the ordinal instead of the cardinal ranking of countries. All results remain unchanged. Observe, however, that we cannot replicate this approach for the other analyses contained in this section, since they can only be conducted using a continuous variable. Results are available upon request from the authors.
} 
low (high) connections with the rest of the network. Finally, when it is equal to zero, it provides evidence for no specific spatial pattern: countries with high and low centrality value are randomly distributed in the geographical space. To complement this analysis, we also compute the Bivariate Global Moran Index (BGMI), which allows to account for spatiotemporal patterns by providing a measure of the extent to which the Katz-Bonacich centrality of one country at time $t$ is influenced by the centrality of neighbouring countries at time $t-1$. The support and the interpretation of the $G M I$ and $B G M I$ is the same: positive and negative values indicate respectively positive and negative spatio-temporal autocorrelation, while values close to zero indicate no spatio-temporal autocorrelation. ${ }^{30}$

The value of the GMI and BGMI is reported in Fig. 3. The figure shows that countries with high centrality values tended to coalesce in the geographical space in the earlier years considered in this analysis: i.e. the GMI is positive. However, the decreasing trend of this index over time suggests that a dispersion process is in place, with countries featuring similar values becoming progressively dispersed in space. This suggests that top-most connected countries in the trade network are changing over time and they tend to be surrounded by low-connected countries more and more. In addition, we observe a constant decrease of the BGMI, indicating that temporal persistence in spatial patterns became negligible over time.

All in all, the evidence thus indicates a multi-centre structure is emerging within Europe, with the raise of high-centrality nodes heterogeneously distributed in the geographical space, and low-connected countries surrounding one of the local centres. This evidence against the presence of a spatial core-periphery structure (i.e. a single geographical cluster benefiting from high spillover effects with respect to the surrounding area) suggests that innovation diffusion increasingly flows across network connections over the time span here considered, following a pattern that is different from that dictated by spatial constraints.

\section{The role of heterogeneity in network spillover effects}

Until now, we have assumed that knowledge spillover effects are described only by parameter $\phi$, which is homogeneous for all countries. Nonetheless, it is plausible to expect that the magnitude of the network externalities exerted by a country might be altered by the characteristics of its trading partners. This is in line, for example, with existing evidence suggesting that policy mix similarity between countries and destination markets may represent important drivers of innovation performances (Fassio, 2018).

Moreover, apart from the already acknowledged role played on knowledge spillovers by the heterogeneity in the network structure (Hoekman et al., 2009), we propose a novel empirical perspective to test our third research question, i.e. if the heterogeneity in the proximity of different country features also explains the mechanisms transforming external knowledge into domestic innovation. Accordingly, we test if and to what extent the benefit from knowledge spillover effects stemming within a group of countries sharing a similar characteristic are different from those originating from inter-group connections. We posit the existence of two groups, $A$ and $B$. We then assume that countries belonging to group $A$

\footnotetext{
${ }^{30}$ For both the GMI and BGMI, we use a row-normalized queen contiguity matrix where two countries are connected if they share a common border.
} 


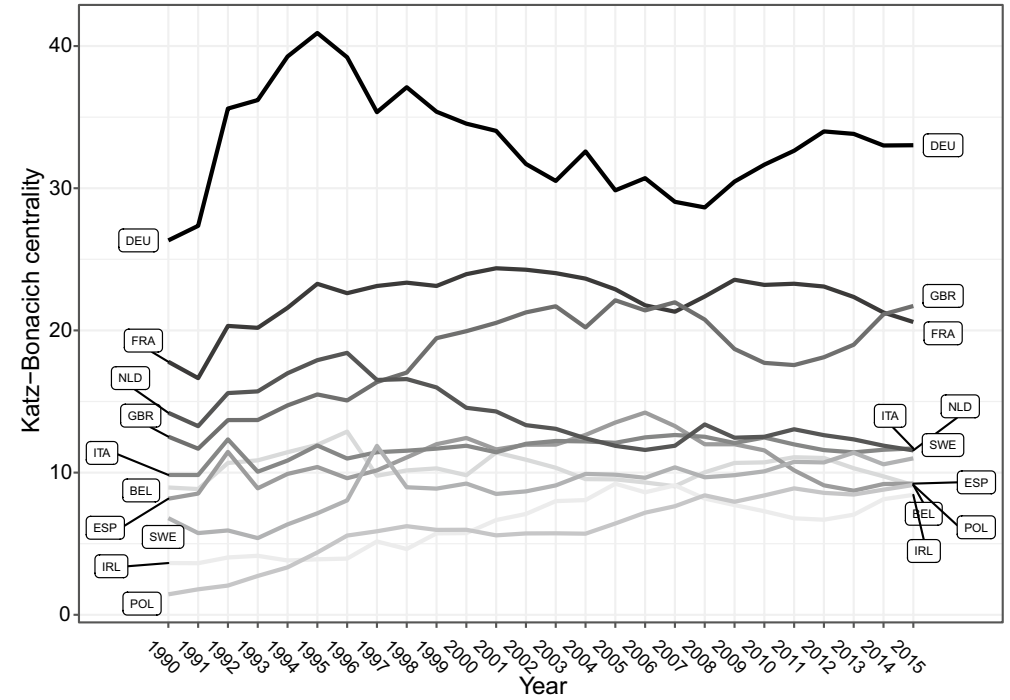

Fig. 1 Top 10 Katz-Bonacich centralities in 2015: evolution over time
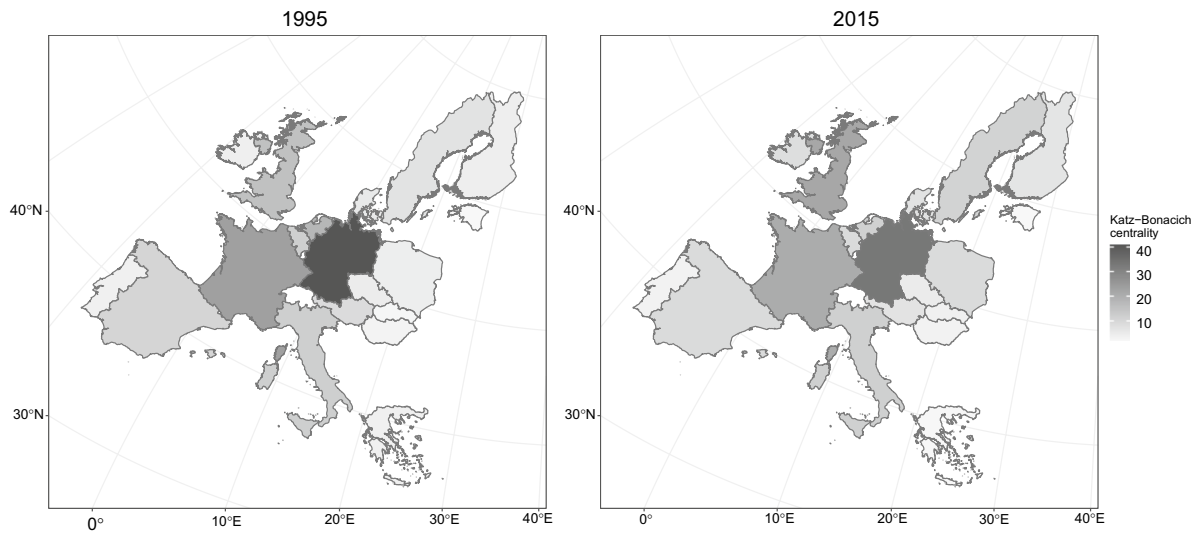

Fig. 2 Spatial distribution of Katz-Bonacich centrality over time

share a given characteristic $z$. On the contrary, countries in group $B$ do not hold characteristic $z$. We then decompose the effect of the spillover of Eq. (9) as follows:

$$
\begin{aligned}
\ln \left(Y_{t}\right)= & \left(I-\theta_{\text {within }} G_{\text {within }}-\theta_{\text {between }} G_{\text {between }}\right)^{-1} \times \\
& \left(\delta+\beta X_{t}+\mu_{i}+\imath_{t}\right)
\end{aligned}
$$

where $G_{\text {within }}$ registers trade partnerships within countries in group $A$, and within countries in group $B$, while $G_{\text {between }}$ records trade partnerships going from countries in group $A$ to countries in group $B$, and viceversa. ${ }^{31}$

$\overline{31 \text { Observe that } G_{\text {within }}+G_{\text {between }}}=G$. 


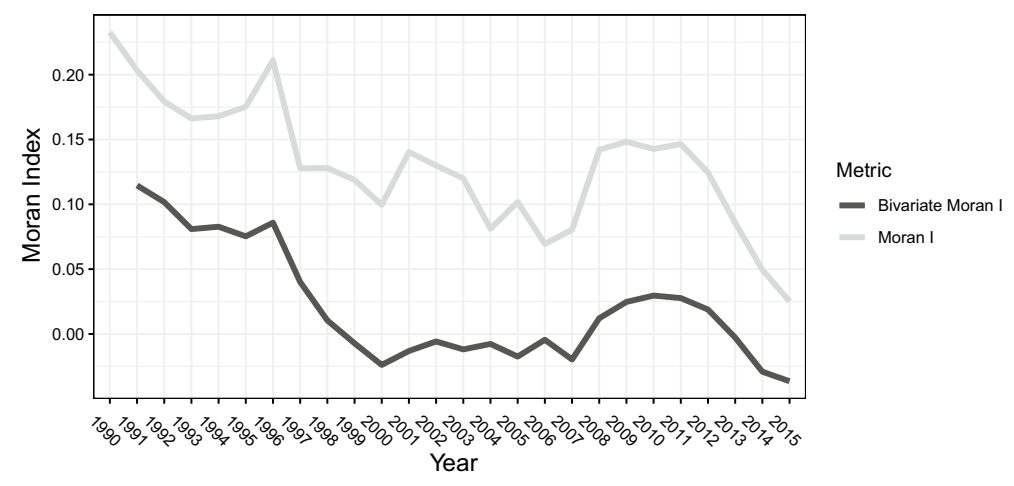

Fig. 3 Spatial distribution of Katz-Bonacich centrality over time: Moran index

It follows that $\theta_{\text {within }}$ assesses the magnitude of network spillovers mediated from withingroup connections independently from the group they belong, and $\theta_{\text {between }}$ measures the magnitude of network spillovers stemming from connections with countries belonging to the other group. We further distinguish intra-group spillover effects by decomposing the effect of parameter $\theta_{\text {within }}$ into $\theta_{\text {within } 1}$, that is the spillover effect running within countries in group $A$, i.e. those holding characteristic $z$, and $\theta_{\text {within } 0}$, that is the spillover effect flowing within countries in group $B$, that is those not featuring characteristic $z$. Eq. (17) then becomes:

$$
\begin{aligned}
\ln \left(Y_{t}\right)= & \left(I-\theta_{\text {within } 0} G_{\text {within } 0}-\theta_{\text {within } 1} G_{\text {within } 1}-\theta_{\text {between }} G_{\text {between }}\right)^{-1} \times \\
& \left(\delta+\beta X_{t}+\mu_{i}+l_{t}\right)
\end{aligned}
$$

where $G_{\text {within } 0}+G_{\text {within } 1}=G_{\text {within }}{ }^{32}$

We estimate Eqs. (17) and (18) by grouping together EU countries according to five different characteristics $z$. The characteristics selected to this purpose are relative to the policy mix dimension, as measured by the variables technology-push and demand-pull, and to the characteristics of the absorptive capacity, as recorded by the variables KET-share, KET$R T A$ and Patent variety. We then assign countries to group $A$ in a given year if they feature a value of $z$ higher than the EU median value of $z$ in that year, and we assign the remaining countries to group $B .^{33}$ The only exception to this rule is when we consider the variable $K E T-R T A$. In this case, countries are assigned to group $A$ in a given year if they feature a value of $z$ higher than 1 , and they are assigned to group $B$ otherwise.

We begin by discussing the results obtained from grouping countries according to the policy mix dimension. Results obtained from estimating a single parameter for withingroup spillover effects (Eq. 17) are reported in Table 2. In Columns (1)-(4)-(7), the

\footnotetext{
32 Observe that the terms $\left(I-\theta_{\text {within }} G_{\text {within }}-\theta_{\text {between }} G_{\text {between }}\right)^{-1} \times q$ and $\left(I-\theta_{\text {within } 0} G_{\text {within } 0}-\theta_{\text {within } 1} G_{\text {within } 1}-\theta_{\text {between }} G_{\text {between }}\right)^{-1} \times q$, where $q$ is a generic factor, represent an extension of Katz-Bonacich centrality. Katz-Bonacich centrality and its extensions belong to a family of eigen-based network centrality measures also referred to as parameter-dependent network centrality measures. The reader interested in the details about this family of network centrality measures is referred to Battaglini et al. (2022).

33 The predictions of our model are robust to the choice of a different threshold value (i.e., the median value) to form groups. Results are available upon request from the authors.
} 


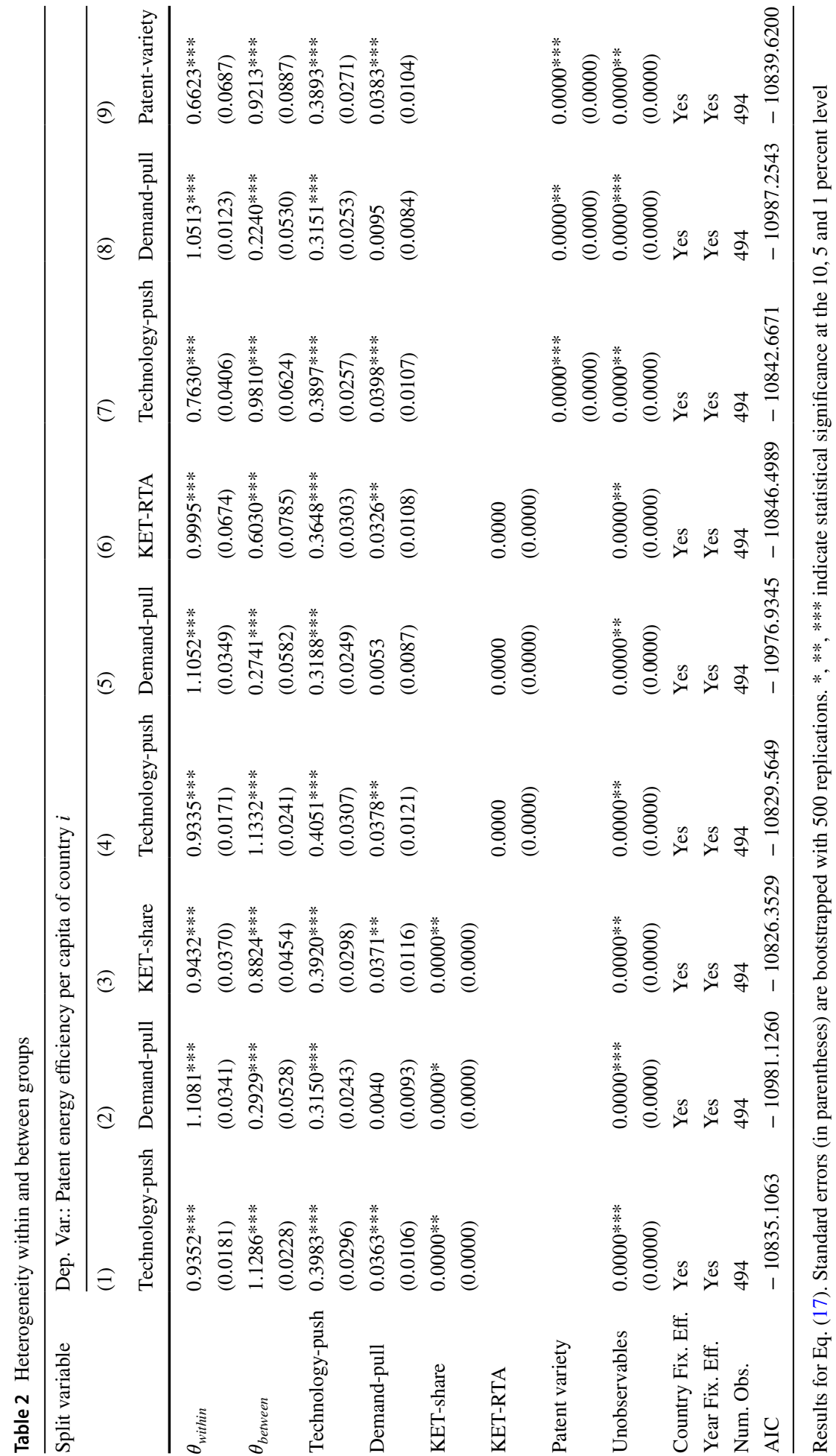


characteristic $z$ used to discriminate between different groups is derived from the Technology-push indicator. In each column, we adopt the same specification, but we alternatively use a different technology variable. The same exercise is presented in Columns (2)-(5)-(8). Here however, the characteristic $z$ used to group countries is that obtained from demandpull. Our results show that $\theta_{\text {within }}$ and $\theta_{\text {between }}$ are positive and statistically significant for both policy indicators regardless of the technology dimension being tested. This leads to the conclusion that knowledge spillover effects arising from learning by export mechanisms have a positive and statistical significant effect, both if trade partners show a policy effort equally committed to the sustainable energy transition, or not.

Interestingly, we observe that the diffusion of innovation between countries is equally affected by all trading partners, regardless of the group they belong according to the variable technology-push: i.e., the magnitude of spillover effects registered within and between different groups is almost equal. On the contrary, when grouping countries according to the variable demand-pull, we observe that spillover effects are significantly larger among trading countries sharing the same level of regulatory stringency (here proxied by the pricebased mechanism), with respect to those registered between countries featuring a different energy taxation profile.

We further explore these findings in Table 3, where we estimate a parameter for the spillover effects of each single group as in Eq. (18). In Columns (1)-(4)-(7) are reported the results relative to the grouping criterion provided by the variable technology-push, while Columns (2)-(5)-(8) refer to the demand-pull characteristic. Notably, we find that the within group spillover effects are statistically significant only among trading partners featuring a high policy stringency. On the contrary, the parameter relative to the spillover effects of countries in the other group is not statistically significant. This implies that the learning by exporting mechanism channelling the diffusion process of EE innovation benefits the exporting country only if both trade partners are characterised by a strong public support to $\mathrm{R} \& \mathrm{D}$ activities and their market demand faces a stringent regulatory setting. These results are robust to alternatively specifications of the technological domain since estimates remain qualitatively unchanged.

We now turn our attention to the results obtained from grouping EU countries according to the absorptive capacity. Estimates relative to Eq. (17), containing a single parameter for within-group spillover effects, are presented in Columns (3)-(6)-(9) of Table 2, which refer to the grouping criterion provided by the variables KET-share, KET-RTA and Patent variety respectively. In each model specification is also included the variable used for deriving the grouping criterion. All model estimates show that both the within and between spillover effects are positive and statistically significant: i.e. trading partners benefit from innovation externalities channelled by the export flows, regardless of whether they share a similar technological specialization or not.

However, when we introduce a control for technological proximity based on KETs characteristics (for both KET-share and KET-RTA), the within dimension is higher than the between one, because the magnitude of the spillover effect is lower when the two trade partners feature a patent portfolio differently specialized in KETs. On the contrary, when controlling for relatedness based on a measure of patent diversification (Patent variety), the spillover effects between different groups are found to be larger than that existing among countries within the same group, revealing that the spillover is magnified when the trading partners are heterogeneously diversified in their knowledge basis.

Given the divergent results about within and between spillovers when considering different measures of the technological dimension, we extend our investigation by estimating a parameter for the spillover effects for each single group using Eq. (18). Results are 


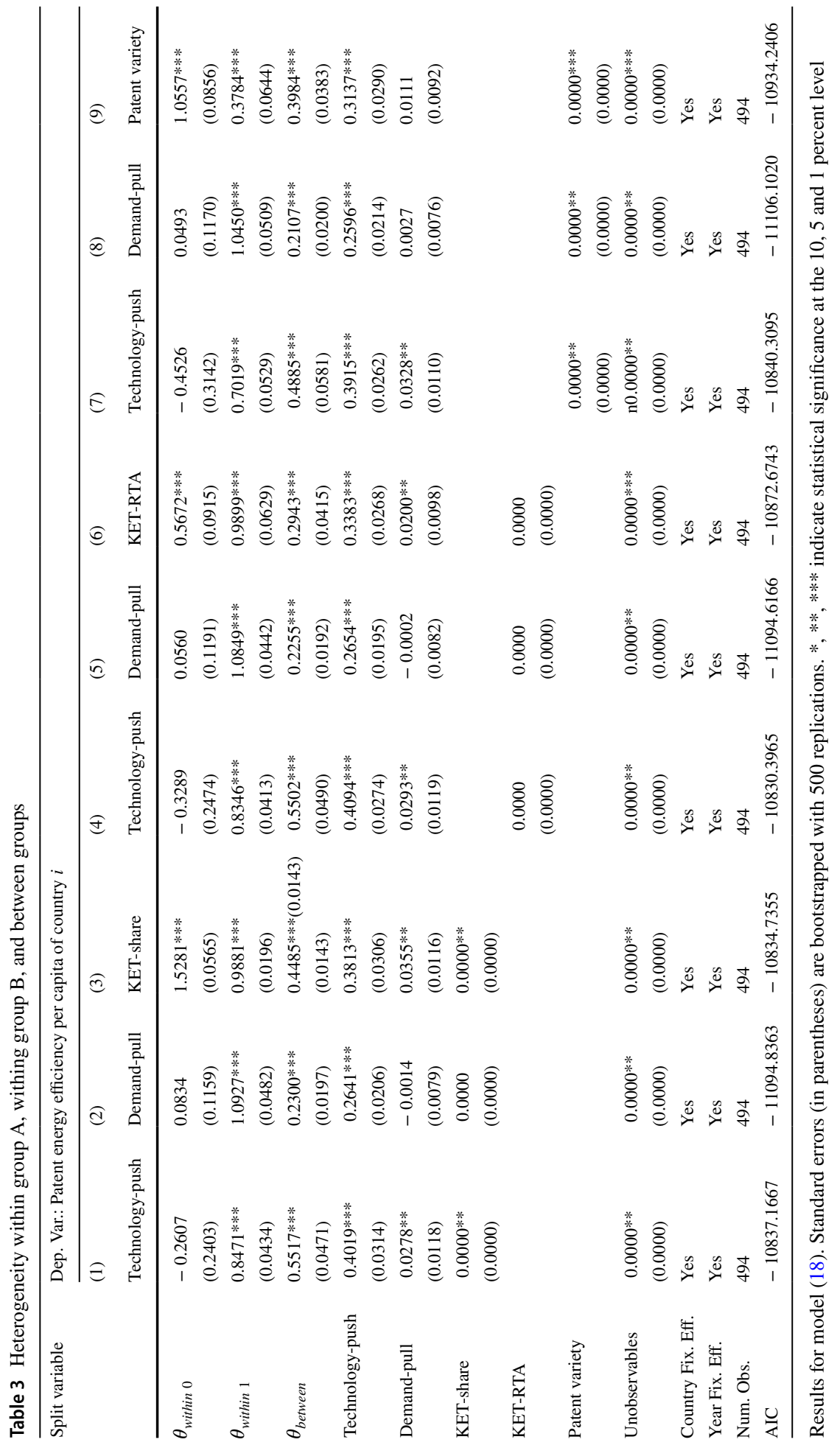


presented in Columns (3)-(6)-(9) of Table 3, with grouping criteria replicating Table 2. First, results in Column (3) reveal that benefits from spillover effects are larger when both trading partners have a low share of EE patents in KETs, meaning that they are more specialized in those domain-specific innovations such as lighting, heating, cooling and home appliances that are directly related to commercialization opportunities on the market. Second, if the specialization in KETs is relatively higher (KET-RTA), knowledge spillovers are larger in country pairs sharing a technological relatedness as in Column (6). This implies that only countries with a RTA in KETs (which can be considered top innovators in this field), exhibit the competences required to fully exploiting the multi-purpose and complementarity gains from KETs, thus benefiting the most from the innovation process of connected trade partners. Third, when looking at technological diversification as a grouping criterion (Patent variety), the largest effect is associated to $\theta_{\text {within } 0}$, suggesting that trading countries benefit from larger spillovers when they can exploit complementarities in knowledge creation in specific EE domains. On the opposite, according to Huang and Chen (2010) and Leten et al. (2007), when patent diversification is too high, the lack of specific competences may have detrimental effects of the innovation performance because the learning by exporting mechanism is harder to activate between over-diversified countries. This last result partly contrasts with the evidence found in Table 2 and suggests that the differentiation adopted by Eq. (18) for group-specific effects produces more precise insights on the innovation diffusion process.

\section{Conclusion}

This paper proposes a network-based methodology to detect the role and impact of knowledge spillovers in the innovation process applied to the case study of residential energy efficiency technologies within the European Union. Given the increasing emphasis of the EU environmental and innovation policy framework on the role played by green energy technologies in fostering a sustainable transition, such methodology contributes in informing the policy mix design by deeply detecting the channels of international knowledge diffusion and suggesting how to reduce transaction costs and maximize policy effectiveness.

Our results, while confirming the key role played by proximity in enabling collaborative innovation by triggering mutual learning, trust formation and frequent interactions, suggest that the multiple dimensions (i.e. cognitive, institutional, organizational, social) of proximity (Boschma and Frenken, 2011; Mahdad et al., 2020) might differently interact with the knowledge diffusion process. In particular, this study allows emphasising four main outcomes related to the relation between proximity and innovation performance.

First, the geography of innovation in Europe has been gradually changing over time. In the nineties, the most central node in the export network who benefited from largest spillover effects was Germany. More recently, other countries became important central nodes and began to substantially benefit from innovation spillover effects. As a result, we observe a slow but constant evolution from a geographical core-periphery structure, with Germany being the main centre, toward a structure where new centers are emerging, such as France, Poland, Sweden and the UK. Consequently, many low-connected countries in the export network are now geographically closer to a centre of the network, and this could have potentially reduced the transaction costs for knowledge sharing typical of a peripheral positioning. 
Second, the regulatory proximity here measured by different instruments forming the policy space is particularly effective in facilitating knowledge spillovers when there is coordination in R\&D support policies.

Third, technological capabilities, relatedness and cognitive proximity are all factors enhancing the probability of agents to interact and exchange knowledge, thus strongly affecting the scope and nature of spillovers. In particular, innovation performances are guided by both internal capabilities and the relatedness in innovation efforts with countries sharing a common economic space. The exploitation of externalities is highest when agents can benefit from complementary specialization processes. On the opposite, an excess in diversification and an innovative process over-specified on KETs reduce the opportunities to transform into innovative capacity the knowledge developed by non-related partners. If, from the one side, enabling technologies move the country's technological frontier forward, given their general-purpose nature and capacity to recombine existing ideas, on the other side such advantage might be a source of constraint by reducing the number of countries from which the innovative process can benefit.

Fourth, the transformation of external knowledge into domestic innovation is also influenced by the heterogeneity in the network structure and the existence of clusters of countries.

Two main policy implications derive from our study. First, the heterogeneity of spillovers across groups characterised by a different policy stringency suggests a relevant implication for the future design of a policy mix strategy oriented to a sustainable energy transition. Even if the climate and energy regulation at the EU level are centralised in the overall design process, the implementation at the country level is still highly heterogeneous. This is mainly justified by the differences in implementation costs across countries, which are left free (or at least they can bargain) to decide the instruments to be adopted and their relative stringency. While this negotiation approach can have short-term benefits for those countries with structural characteristics that impede a rapid transition process, at the same time it reduces opportunities to capture those knowledge externalities coming from countries that are accelerating their transition process, with longer-term losses. Accordingly, a higher policy coordination will be essential to faster knowledge complementarity exploitation.

Second, further efforts are required to speed up the convergence process by developing different economic centres to completely transform the previous core-periphery structure of the EU market into a multi-centre structure. To this purpose, renewed efforts in the smart specialization strategy (Foray et al., 2011; Uyarra et al., 2014), tailored to help regions and countries to identify their specific place-based and technology-domain policies, could bring to catch the opportunities from knowledge externalities in a faster and cost-effective transition process. Our methodology could be used as an analytical basis of this policy development for instance by applying it to different green technology domains forming the sustainable energy strategy in order to completely replace the "one-size fits all" policy design.

\section{Appendix}

See Tables 4, 5, 6, 7 and Fig. 4 
Table 4 First stage

\begin{tabular}{|c|c|c|c|c|c|}
\hline & \multicolumn{5}{|c|}{ Dep. var.: export between country $i$ and country $j$} \\
\hline & (1) & (2) & (3) & (4) & $(5)$ \\
\hline $\ln (\mathrm{GDP}) \mathrm{pc}$ & $\begin{array}{l}-0.0338 * * * \\
(0.0033)\end{array}$ & $\begin{array}{l}-0.0350 * * * \\
(0.0034)\end{array}$ & $\begin{array}{l}-0.0280 * * * \\
(0.0036)\end{array}$ & $\begin{array}{l}-0.0294 * * * \\
(0.0036)\end{array}$ & $\begin{array}{l}-0.0299 * * * \\
(0.0036)\end{array}$ \\
\hline Technology-push $(* 100)$ & $\begin{array}{l}-1.5904 * * \\
(0.6222)\end{array}$ & $\begin{array}{l}-1.5820 * * \\
(0.6220)\end{array}$ & $\begin{array}{l}-1.2141^{*} \\
(0.6239)\end{array}$ & $\begin{array}{l}-1.3912 * * \\
(0.6227)\end{array}$ & $\begin{array}{l}-1.2585^{* *} \\
(0.6266)\end{array}$ \\
\hline Demand-pull $(* 100)$ & & $\begin{array}{l}-0.7775^{* *} \\
(0.2715)\end{array}$ & $\begin{array}{l}-0.7455^{* *} \\
(0.2710)\end{array}$ & $\begin{array}{l}-0.7343^{* *} \\
(0.2714)\end{array}$ & $\begin{array}{l}-0.7615^{* *} \\
(0.2713)\end{array}$ \\
\hline KET-share & & & $\begin{array}{l}-0.0310 * * * \\
(0.0053)\end{array}$ & & \\
\hline KET-RTA & & & & $\begin{array}{l}-0.0090^{* * * *} \\
(0.0020)\end{array}$ & \\
\hline Patent variety & & & & & $\begin{array}{l}-0.0182 * * * \\
(0.0045)\end{array}$ \\
\hline Country Fix. Eff. & Yes & Yes & Yes & Yes & Yes \\
\hline Year Fix. Eff. & Yes & Yes & Yes & Yes & Yes \\
\hline Num. Obs. & 8892 & 8892 & 8892 & 8892 & 8892 \\
\hline AIC & -20880.9140 & -20887.1686 & -20920.0967 & -20905.8304 & -20901.4757 \\
\hline
\end{tabular}

Results for model (10). Column (1), (2), (3), (4), (5) report the estimates of the "first stage" for the model estimated in Table (1), Column (3), (4), (5), (6), (7) respectively. Standard errors are reported in parentheses. *, **, *** indicate statistical significance at the 10,5 and 1 percent level

Table 5 Quantification of the effects of technology-push

\begin{tabular}{|c|c|c|c|c|c|c|c|}
\hline Direct effects & $\beta$ & Mean & St. Dev. & $\operatorname{Max}$ & Min & & \\
\hline & 0.4815 & 0.5022 & 0.0580 & 0.7120 & 0.4314 & & \\
\hline \multirow[t]{2}{*}{ Indirect effects } & & & Mean & & St. Dev. & Max & Min \\
\hline & & & 0.0742 & & 0.0748 & 0.4495 & 0.0004 \\
\hline
\end{tabular}

Quantification of the mean marginal direct and indirect effects presented in Table 1, Column (3). For comparison purposes, Column $\beta$ contains the estimated coefficient reported in Table 1, Column (1) 


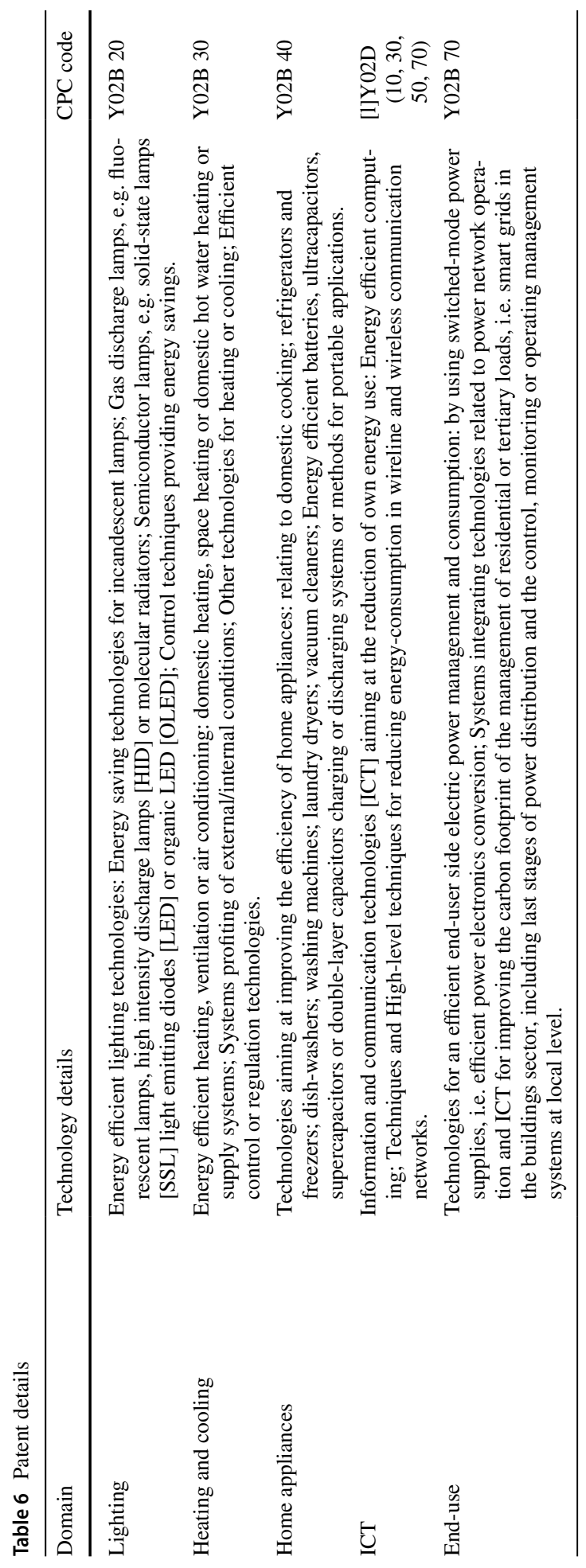




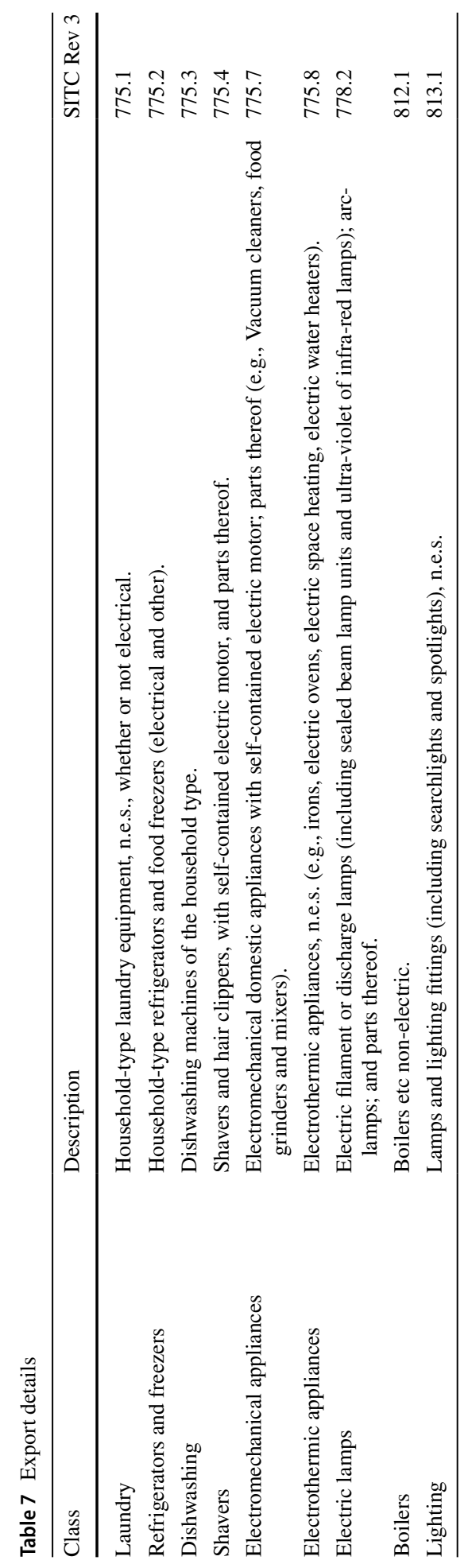


(a) 1995

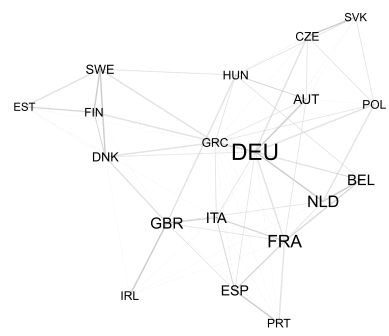

(b) 2005

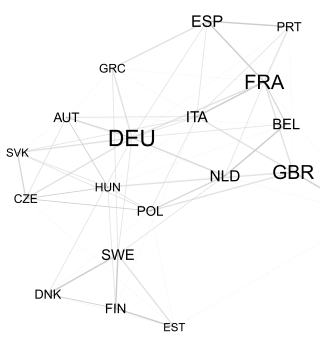

(c) 2015

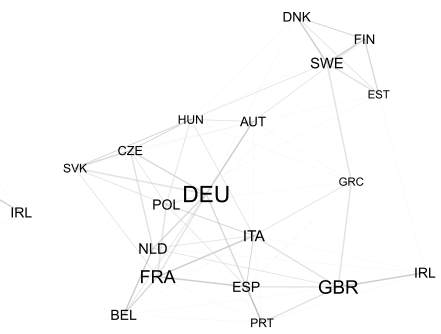

Fig. 4 Network of exports over time. In each panel, we represent the trade network of countries respectively in 1995 (left panel), 2005 (central panel), 2015 (right panel). For visualization purposes, we consider only the backbone of the network, by showing only top five export flows originating from each country. The size of the nodes (countries) is proportional to their Katz-Bonacich centrality, meaning that larger nodes identify those countries who have benefited the most from technological spillover by maintaining or acquiring a high network centrality over time. The algorithm used for generating the layout (Fruchterman and Reingold, 1991) places nodes with shared connections closer to one another, thus it visually stresses peculiar patterns of interactions (i.e. trade clusters). The name of the countries is indicated using the ISO3 code system

Funding Italian Ministry of University andResearch, Scientific Research Program ofNational Relevance (PRIN)(Grant No.: 20177J2LS9_003)

Open Access This article is licensed under a Creative Commons Attribution 4.0 International License, which permits use, sharing, adaptation, distribution and reproduction in any medium or format, as long as you give appropriate credit to the original author(s) and the source, provide a link to the Creative Commons licence, and indicate if changes were made. The images or other third party material in this article are included in the article's Creative Commons licence, unless indicated otherwise in a credit line to the material. If material is not included in the article's Creative Commons licence and your intended use is not permitted by statutory regulation or exceeds the permitted use, you will need to obtain permission directly from the copyright holder. To view a copy of this licence, visit http://creativecommons.org/licenses/by/4.0/.

\section{References}

Andersson, M., \& Lööf, H. (2009). Learning-by-exporting revisited: The role of intensity and persistence. Scandinavian Journal of Economics, 111(4), 893-916.

Anselin, L., Varga, A., \& Acs, Z. (1997). Local geographic spillovers between university research and high technology innovations. Journal of Urban Economics, 42(3), 422-448.

Antonelli, C., Crespi, F., \& Quatraro, F. (2020). Knowledge complexity and the mechanisms of knowledge generation and exploitation: The European evidence. Research Policy, pp 104081.

Autant-Bernard, C. (2012). Spatial econometrics of innovation: Recent contributions and research perspectives. Spatial Economic Analysis, 7(4), 403-419.

Balassa, B. (1965). Trade liberalisation and "revealed" comparative advantage. The Manchester School, $33(2), 99-123$.

Balland, P.-A., Boschma, R., Crespo, J., \& Rigby, D. L. (2019). Smart specialization policy in the European Union: Relatedness, knowledge complexity and regional diversification. Regional Studies, 53(9), 1252-1268.

Ballester, C., Calvó-Armengol, A., \& Zenou, Y. (2006). Who's who in networks. Wanted: The key player. Econometrica, 74(5), 1403-1417.

Barbieri, N., Ghisetti, C., Gilli, M., Marin, G., \& Nicolli, F. (2016). A survey of the literature on environmental innovation based on main path analysis. Journal of Economic Surveys, 30(3), 596-623.

Battaglini, M., Leone Sciabolazza, V., Patacchini, E., \& Peng, S. (2022). econet: An R package for parameter-dependent network centrality measures. Journal of Statistical Software. Forthcoming. Available at https://cran.r-project.org/web/packages/econet/vignettes/econet.pdf. 
Bolland, J. M. (1988). Sorting out centrality: An analysis of the performance of four centrality models in real and simulated networks. Social Networks, 10(3), 233-253.

Bonacich, P. (1972). Factoring and weighting approaches to status scores and clique identification. Journal of Mathematical Sociology, 2(1), 113-120.

Bonacich, P. (1987). Power and centrality: A family of measures. American Journal of Sociology, 92(5), 1170-1182.

Boschma, R., \& Frenken, K. (2011). Technological relatedness, related variety and economic geography. In P. Cooke, B. Asheim, R. Boschma, R. Martin, D. Schwartz, \& F. Tödtling (Eds.), Handbook of regional innovation and growth. Edward Elgar Publishing.

Bottazzi, L., \& Peri, G. (2007). The international dynamics of R\&D and innovation in the long run and in the short run. The Economic Journal, 117(518), 486-511.

Bustos, P. (2011). Trade liberalization, exports, and technology upgrading: Evidence on the impact of MERCOSUR on Argentinian firms. American Economic Review, 101(1), 304-340.

Cantner, U., \& Malerba, F. (2007). Innovation, industrial dynamics and structural transformation. Springer.

Cantwell, J. (1989). Technological innovation and multinational corporations. Blackwell.

Charbonneau, K. B. (2017). Multiple fixed effects in binary response panel data models. The Econometrics Journal, 20(3), S1-S13.

Chiu, Y.-C., Lai, H.-C., Lee, T.-Y., \& Liaw, Y.-C. (2008). Technological diversification, complementary assets, and performance. Technological Forecasting and Social Change, 75(6), 875-892.

Clarke, N. S. (2018). The basics of patent searching. World Patent Information, 54, S4-S10.

Costantini, V., Crespi, F., Marin, G., \& Paglialunga, E. (2017a). Eco-innovation, sustainable supply chains and environmental performance in European industries. Journal of Cleaner Production, 155, 141-154.

Costantini, V., Crespi, F., \& Palma, A. (2017b). Characterizing the policy mix and its impact on eco-innovation: A patent analysis of energy-efficient technologies. Research Policy, 46(4), 799-819.

De Loecker, J. (2013). Detecting learning by exporting. American Economic Journal: Microeconomics, 5(3), 1-21.

Dechezleprêtre, A., \& Glachant, M. (2014). Does foreign environmental policy influence domestic innovation? Evidence from the wind industry. Environmental and Resource Economics, 58(3), 391-413.

Dechezleprêtre, A., Neumayer, E., \& Perkins, R. (2015). Environmental regulation and the cross-border diffusion of new technology: Evidence from automobile patents. Research Policy, 44(1), 244-257.

Del Río, P. (2010). Analysing the interactions between renewable energy promotion and energy efficiency support schemes: The impact of different instruments and design elements. Energy Policy, 38(9), 4978-4989.

EC,. (2014). High-level expert group on key enabling technologies: KETs for a competitive Europe. Directorate General Enterprise and Industry, European Commission.

EC. (2019). High-level expert group on key enabling technologies: KETs for a competitive Europe. DG Energy, European Commission.

Enkel, E., Groemminger, A., \& Heil, S. (2018). Managing technological distance in internal and external collaborations: Absorptive capacity routines and social integration for innovation. The Journal of Technology Transfer, 43(5), 1257-1290.

Evangelista, R., Meliciani, V., \& Vezzani, A. (2018). Specialisation in key enabling technologies and regional growth in Europe. Economics of Innovation and New Technology, 27(3), 273-289.

Fassio, C. (2018). Export-led innovation: The role of export destinations. Industrial and Corporate Change, 27(1), 149-171.

Fiorini, A., Georgakaki, A., Pasimeni, F., \& Tzimas, E. (2017). Monitoring R\&I in low-carbon energy technologies. EUR.

Foray, D., David, P. A., \& Hall, B. (2009). Knowledge economists policy brief $n$ 9. European Commission.

Foray, D., David, P. A., \& Hall, B. H. (2011). Smart specialization. From academic idea to political instrument, the surprising career of a concept and the difficulties involved in its implementation. EPFL-MTEI working paper, November 2011.

Fruchterman, T. M. J., \& Reingold, E. M. (1991). Graph drawing by force-directed placement. Software: Practice and Experience, 21(11), 1129-1164.

García, F., Avella, L., \& Fernández, E. (2012). Learning from exporting: The moderating effect of technological capabilities. International business review, 21(6), 1099-1111.

Garcia-Vega, M. (2006). Does technological diversification promote innovation?: An empirical analysis for European firms. Research Policy, 35(2), 230-246.

Ghoshal, A., \& Barabási, A. (2011). Ranking stability and super-stable nodes in complex networks. Nature Communications, 2, 394.

Graham, B. S. (2017). An econometric model of network formation with degree heterogeneity. Econometrica, 85(4), 1033-1063. 
Griliches, Z. (1979). Issues in assessing the contribution of research and development to. Bell Journal of Economics, 10, 92-116.

Griliches, Z. (1990). Patent statistics as economic indicators: A survey. Journal of Economic Literature, 28(4), 1661-1707.

Hall, B. (2005). A note on the bias in herfindahl-type measures based on count data. Revue d'Économie Industrielle, 110(1), 149-156.

Hall, B. H., Jaffe, A., \& Trajtenberg, M. (2005). Market value and patent citations. RAND Journal of Economics, 36, 16-38.

Heckman, J. J. (1979). Sample selection bias as a specification error. Econometrica, 47, 153-161.

Hidalgo, C. A. (2021). Economic complexity theory and applications. Nature Reviews Physics, 3, 1-22.

Hidalgo, C. A., \& Hausmann, R. (2009). The building blocks of economic complexity. Proceedings of the National Academy of Sciences, 106(26), 10570-10575.

Ho, C.-Y., Wang, W., \& Yu, J. (2018). International knowledge spillover through trade: A time-varying spatial panel data approach. Economics Letters, 162, 30-33.

Hoekman, J., Frenken, K., \& Van Oort, F. (2009). The geography of collaborative knowledge production in Europe. The Annals of Regional Science, 43(3), 721-738.

Huang, Y.-F., \& Chen, C.-J. (2010). The impact of technological diversity and organizational slack on innovation. Technovation, 30(7-8), 420-428.

Jackson, M. O., Rogers, B. W., \& Zenou, Y. (2017). The economic consequences of social-network structure. Journal of Economic Literature, 55(1), 49-95.

Jaffe, A. B. (1986). Technological opportunity and spillovers of R \& D: Evidence from firms' patents, profits, and market value. American Economic Review, 76(5), 984-1001.

Jaffe, A. B. (1989). Real effects of academic research. American Economic Review, 79(5), 957-970.

Jaffe, A. B., \& Trajtenberg, M. (2002). Patents, citations, and innovations: A window on the knowledge economy. MIT Press.

Johnstone, N., Haščič, I., \& Popp, D. (2010). Renewable energy policies and technological innovation: Evidence based on patent counts. Environmental and Resource Economics, 45(1), 133-155.

Katz, L. (1953). A new status index derived from sociometric analysis. Psychometrika, 18(1), 39-43.

Kemp, R., \& Pearson, P. (2007). Final report MEI project about measuring eco-innovation. UM Merit, Maastricht, 10, 2.

Kim, J., Lee, C.-Y., \& Cho, Y. (2016). Technological diversification, core-technology competence, and firm growth. Research Policy, 45(1), 113-124.

Kim, J., \& Lee, S. (2015). Patent databases for innovation studies: A comparative analysis of USPTO, EPO, JPO and KIPO. Technological Forecasting and Social Change, 92, 332-345.

Konno, T. (2016). Knowledge spillover processes as complex networks. Physica A: Statistical Mechanics and its Applications, 462, 1207-1214.

Lee, D. (2020). The role of R\&D and input trade in productivity growth: Innovation and technology spillovers. The Journal of Technology Transfer, 45(3), 908-928.

Leten, B., Belderbos, R., \& Van Looy, B. (2007). Technological diversification, coherence, and performance of firms. Journal of Product Innovation Management, 24(6), 567-579.

Li, Y., \& Bosworth, D. (2020). R\&D spillovers in a supply chain and productivity performance in British firms. The Journal of Technology Transfer, 45(1), 177-204.

Lileeva, A., \& Trefler, D. (2010). Improved access to foreign markets raises plant-level productivity... for some plants. The Quarterly Journal of Economics, 125(3), 1051-1099.

Lin, C., \& Chang, C.-C. (2015). The effect of technological diversification on organizational performance: An empirical study of S\&P 500 manufacturing firms. Technological Forecasting and Social Change, 90, 575-586.

Liu, X., \& Buck, T. (2007). Innovation performance and channels for international technology spillovers: Evidence from Chinese high-tech industries. Research Policy, 36(3), 355-366.

Love, J. H., \& Ganotakis, P. (2013). Learning by exporting: Lessons from high-technology SMEs. International Business Review, 22(1), 1-17.

Mahdad, M., Minh, T. T., Bogers, M. L., \& Piccaluga, A. (2020). Joint university-industry laboratories through the lens of proximity dimensions: moving beyond geographical proximity. International Journal of Innovation Science, 12(4), 433-456.

Mancusi, M. L. (2008). International spillovers and absorptive capacity: A cross-country cross-sector analysis based on patents and citations. Journal of International Economics, 76(2), 155-165.

Marin, G., \& Zanfei, A. (2019). Does host market regulation induce cross-border environmental innovation? The World Economy, 42(7), 2089-2119.

Mealy, P., \& Teytelboym, A. (2020). Economic complexity and the green economy. Research Policy (pp. 103948). 
Mitze, T., \& Makkonen, T. (2020). When interaction matters: The contingent effects of spatial knowledge spillovers and internal R\&I on firm productivity. The Journal of Technology Transfer, 45(4), 1088-1120.

Montresor, S., \& Quatraro, F. (2017). Regional branching and key enabling technologies: Evidence from European patent data. Economic Geography, 93(4), 367-396.

Montresor, S., \& Quatraro, F. (2020). Green technologies and Smart Specialisation Strategies: A European patent-based analysis of the intertwining of technological relatedness and key enabling technologies. Regional Studies, 54(10), 1354-1365.

Nill, J., \& Kemp, R. (2009). Evolutionary approaches for sustainable innovation policies: From niche to paradigm? Research Policy, 38(4), 668-680.

Noailly, J. (2012). Improving the energy efficiency of buildings: The impact of environmental policy on technological innovation. Energy Economics, 34(3), 795-806.

OECD (2009). The perpetual inventory method - overview. In OECD, Measuring Capital. OECD Manual 2009, 2nd edn. OECD Publishing, Paris. Organization for Economic Cooperation and Development, (October).

Peters, M., Schneider, M., Griesshaber, T., \& Hoffmann, V. H. (2012). The impact of technology-push and demand-pull policies on technical change-Does the locus of policies matter? Research Policy, 41(8), 1296-1308.

Popp, D. (2002). Induced innovation and energy prices. American Economic Review, 92(1), 160-180.

Porter, M. E., \& Van der Linde, C. (1995). Toward a new conception of the environment-competitiveness relationship. Journal of Economic Perspectives, 9(4), 97-118.

Pugliese, E., Chiarotti, G. L., Zaccaria, A., \& Pietronero, L. (2017). Complex economies have a lateral escape from the poverty trap. PloS One, 12(1), e0168540.

Quintana-García, C., \& Benavides-Velasco, C. A. (2008). Innovative competence, exploration and exploitation: The influence of technological diversification. Research Policy, 37(3), 492-507.

Reichardt, K., \& Rogge, K. (2016). How the policy mix impacts innovation: Findings from company case studies on offshore wind in Germany. Environmental Innovation and Societal Transitions, 18, 62-81.

Rogge, K. S., \& Reichardt, K. (2016). Policy mixes for sustainability transitions: An extended concept and framework for analysis. Research Policy, 45(8), 1620-1635.

Rosenow, J., Fawcett, T., Eyre, N., \& Oikonomou, V. (2016). Energy efficiency and the policy mix. Building Research \& Information, 44(5-6), 562-574.

Rosenow, J., Kern, F., \& Rogge, K. (2017). The need for comprehensive and well targeted instrument mixes to stimulate energy transitions: The case of energy efficiency policy. Energy Research \& Social Science, 33, 95-104.

Salomon, R., \& Jin, B. (2008). Does knowledge spill to leaders or laggards? Exploring industry heterogeneity in learning by exporting. Journal of International Business Studies, 39(1), 132-150.

Santoalha, A., \& Boschma, R. (2020). Diversifying in green technologies in European regions: Does political support matter? Regional Studies, forthcoming.

Sbardella, A., Perruchas, F., Napolitano, L., Barbieri, N., \& Consoli, D. (2018). Green technology fitness. Entropy, 20(10), 776.

Soete, L. (1987). The impact of technological innovation on international trade patterns: The evidence reconsidered. Research Policy, 16(2-4), 101-130.

Strunz, S. (2014). The German energy transition as a regime shift. Ecological Economics, 100, 150-158.

Tacchella, A., Cristelli, M., Caldarelli, G., Gabrielli, A., \& Pietronero, L. (2012). A new metrics for countries' fitness and products' complexity. Scientific Reports, 2(1), 1-7.

Tacchella, A., Cristelli, M., Caldarelli, G., Gabrielli, A., \& Pietronero, L. (2013). Economic complexity: Conceptual grounding of a new metrics for global competitiveness. Journal of Economic Dynamics and Control, 37(8), 1683-1691.

Uyarra, E., Sörvik, J., \& Midtkandal, I. (2014). Inter-regional collaboration in research and innovation strategies for smart specialisation (RIS3). Joint Research Centre.

Verdolini, E., \& Galeotti, M. (2011). At home and abroad: An empirical analysis of innovation and diffusion in energy technologies. Journal of Environmental Economics and Management, 61(2), 119-134.

Zhao, S., Jiang, Y., \& Wang, S. (2019). Innovation stages, knowledge spillover, and green economy development: Moderating role of absorptive capacity and environmental regulation. Environmental Science and Pollution Research, 26(24), 25312-25325.

Publisher's Note Springer Nature remains neutral with regard to jurisdictional claims in published maps and institutional affiliations. 